\title{
Histopathology
}

\section{Pathology and biology of peripheral T-cell lymphoma}

\begin{tabular}{|r|l|}
\hline Journal: & Histopathology \\
\hline Manuscript ID: & HISTOP-09-10-0495 \\
\hline Wiley - Manuscript type: & Review \\
\hline $\begin{array}{r}\text { Date Submitted by the } \\
\text { Author: }\end{array}$ & 06-Sep-2010 \\
\hline Complete List of Authors: & $\begin{array}{l}\text { de Leval, Laurence; CHU Sart-Tilman, Pathology } \\
\text { Gaulard, Philippe; Hopital Henri Mondor, Pathology }\end{array}$ \\
\hline Keywords: & Pathology, Biology, T-cell lymphomas, Pathogenesis \\
\hline &
\end{tabular}

\section{SCHOLARONE}

Manuscripts 


\title{
Pathology and biology of peripheral T-cell lymphomas
}

\author{
Laurence de Leval ${ }^{1}$ and Philippe Gaulard ${ }^{2}$ \\ From: ${ }^{1}$ the Pathology Institute, CHUV Lausanne, Switzerland; and ${ }^{2}$ the Pathology \\ Department and Inserm U955, Hôpital Henri Mondor, Créteil, France.
}

Address correspondence:

Laurence de Leval, MD PhD

Institute of Pathology,

25 rue du Bugnon,

CH- 1011 - Lausanne

Switzerland

Phone: +41213147194

Fax: +41213147205

E-mail: Laurence.deLeval@chuv.ch 


\section{INTRODUCTION}

Peripheral T-cell lymphomas (PTCLs) comprise a variety of uncommon and overall rare malignancies derived from mature (post-thymic) T cells and NK cells, altogether accounting for less than $15 \%$ of all non-Hodgkin lymphomas worlwide. ${ }^{1}$

The WHO approach to lymphoma classification relies on a combination of morphologic, immunophenotypic, genetic and clinical features, and attempts to correlate disease entities with a normal cellular counterpart. ${ }^{2}$ While these principles have led to the comprehensive delineation of B-cell lymphoma entities, their application to NK/T-cell-derived neoplasms is hampered by several difficulties. Firstly, distinct T/NK-cell tumors have a broad range of cellular composition, distinct PTCLs diseases lack distinct immunophenotypic profiles, and there is significant morphologic and immunophenotypic overlap across different entities. Moreover, with few exceptions, notably the rearrangement of the anaplastic lymhpoma kinase ( $A L K)$ gene in ALK-positive anaplastic large cell lymphoma (ALCL), few recurrent genetic alterations have been identified in PTCLs, and poorly contribute to their categorization. Conversely, the clinical features and anatomic location of the disease are critical in defining NK/T lymphoma entities, which can be grouped according to their presentation as disseminated, predominantly extranodal or cutaneous, or predominantly nodal diseases (Table 1). The normal cell counterparts of the NK and T-cell lineages involved in innate and adaptive immunity, constitute a complex system with numerous functional subsets displaying marked phenotypic diversity and also evidence of plasticity. Although there is increasing evidence that the cell of origin is a major determinant for the delineation of several PTCL entities ${ }^{3,4,5}$, however, the cellular derivation of most entities remains poorly characterized and/or may be heterogeneous (Figure 1).

Strikingly, the epidemiology of PTCLs shows important geographic variations, which partly overlap with the endemy of certain viral infections and are also linked to the heterogeneous distribution of genetic backgrounds influencing the immune response to peculiar antigens. ${ }^{1,6}$ The overall incidence of PTCLs is higher in Asia and central/south America than in western countries, especially of those induced by the human T-lymphotropic virus-1 (HTLV1) and by the Epstein-Barr virus (EBV). Conversely, enteropathy-associated T-cell lymphoma is predominantly encountered in Northern Europe where celiac disease is more prevalent. 
PTCLs pose challenges in several respects. Clinically, most entities are aggressive diseases with overall poor response to classical treatments and carry a dismal prognosis. The diagnosis of PTCL is often difficult, as many cases comprise a reactive cellular infiltrate which may mask the neoplastic cell population. Moreover, demonstration of T-cell clonality is not feasible by routine immunophenotyping and usually requires molecular testing. The complexity of the biology and pathophysiology of PTCLs is only partly deciphered. Research in that field has been compounded by the concurrent rarity and diversity of PTCLs hampering the collection of homogeneous cohorts of patients, the heterogeneity of the pathological samples, the absence of cell lines representative of the major entities, and the lack of good animal models. In recent years, however, novel insights have been gained from genome-wide profiling analyses. ${ }^{4,-13}$

Here, we will summarize the current knowledge on the pathobiological features of selected peripheral NK/T-cell neoplasms. The review will be focused on selected disease entities manifesting as tissue infiltrates primarily in extranodal sites and lymph nodes.

\section{PRIMARILY EXTRANODAL PTCL ENTITIES}

Not taking into consideration the most common forms of primary cutaneous T-cell lymphomas (Mycosis fungoides/Sezary syndrome and primary cutaneous CD30+ T-cell lymphoproliferations) that have not been incorporated systematically into the recent epidemiological studies, PTCL entities with primary extranodal presentation are overall less common than nodal PTCLs, especially in Europe and North America (Table 2). ${ }^{6}$ It is noteworthy that neoplasms derived from cells of the innate immune system (mostly NK-cell and gamma-delta T-cell lymphomas) have a specific tropism for extranodal sites. Remarkably, the different extranodal PTCL entities - defined primarily by their clinical features and immunophenotype - share several common features ${ }^{14,15}$ Within each entity, the cytomorphology of the tumors is highly variable, in contrast to a virtually constant cytotoxic profile. Clinically, lymph node involvement is rare, dissemination to other extranodal sites is common, the occurrence of a hemophagocytic syndrome is relatively frequent and the clinical evolution of the patients is usually aggressive while the present therapeutic strategies are limited. Immune stimulation by 
specific antigens including EBV-and gluten-associated factors, are recognized to be involved in the pathogenesis of some entities.

\section{A. Extranodal NK/T-cell lymphoma, nasal type}

Extranodal NK/TCL is not exceptional in western countries, but predominantly affects middle-aged men in Asia, Mexico and South America. ${ }^{16}$ It presents as tumors or destructive lesions in the nasal cavity, maxillary sinuses or palate, previously referred to as "lethal midline granuloma". Despite a localized presentation in most patients, the prognosis is poor with around 40-50\% 5-year survival rate and tendency for local relapses or dissemination to other extranodal sites, such as the skin. ${ }^{16,17}$

Extranodal NK/TCL is morphologically heterogeneous with a cytological spectrum ranging from monomorphic small/medium-sized to large cell lymphomas, and is characterized by frequent features of angioinvasion and angiocentrism, and common necrosis, accounting for frequent diagnostic difficulties on small biopsies (Figure 2A2B). Neoplastic cells express cytoplasmic CD3 (CD3\&+), are CD2+, CD5-, CD56+ (Figure 2C), and have an activated cytotoxic profile reflected in the combined expression of T-cell intracellular antigen (TIA)1, which is also expressed in nonactivated cytotoxic cells, together with perforin, granzyme B, which are markers of active cytotoxicity. By definition, all cases are associated with EBV, best demonstrated by in situ hybridization (Figure 2D). ${ }^{2}$

In most cases, the tumor cells do not express the T-cell receptor (TCR)/CD3 complex at the cell membrane and have TCR genes in a germline configuration, consistent with a NK-cell derivation. A small proportion of cases with expression of an $\gamma \delta$ or $\alpha \beta$ TCR, have clonal TCR genes rerrangements and likely derive from cytotoxic T lymphocytes, hence the "NK/T-cell" terminology. ${ }^{2}$

The pathogenesis of extranodal NKTCL remains unclear, but several lines of evidence point at EBV as a major player. EBV is clonally present in an episomal form in the tumour cells and exerts oncogenic effects through the production of cytokines such as IL-9 and IL-10. ${ }^{18}$ EBV-induced upregulation of IP10/MIP2 chemokines may contribute to vascular damage and secondary necrosis. ${ }^{19}$ while TNF $\alpha$ production may explain the common hemophagocytic syndrome. Partial deletion of chromosome 6 (6q21-25) is a recurrent aberration in extranodal NKTCL. ${ }^{20,21}$ Several candidate tumour 
suppressor genes, such as PRDM1, ATG5, AIM1 and HACE1, are mapping to that region and their inactivation by deletion and/or methylation might be involved in lymphomagenesis. ${ }^{13,22}$ At the genome-wide level, the molecular signature of extranodal NKTCL is distinct from that of PTCL, not otherwise specified, including overexpression of granzyme H. Compared to normal NK cells, extranodal NKTCL is characterized by activation of PDGFRA, and of the AKT, Janus kinase-signal transducers and activators of transcription, and nuclear factor-kappaB pathways, which might represent targets for the development of novel therapeutic options. ${ }^{22,23}$

Several mechanisms have been evidenced that may contribute to the poor response of extranodal NKTCL to chemotherapy: deregulation of apoptotic pathways due to FAS gene alterations and TP53 mutations ${ }^{24,25}$, expression of the multidrug resistance (MDR) 1 gene product $\mathrm{P}$-glycoprotein, immune escape by defective CD94/NKG2A NK-cell receptors ${ }^{26}$.

Lymphomas morphologically, and phenotypically similar to the nasal NKTCL, may present in other localizations, especially in the skin, gastrointestinal tract or testis. These "extranasal NK/T cell lymphomas" tend to have a more adverse clinical outcome than nasal cases. ${ }^{27}$

\section{B. Subcutaneous panniculitis-like T-cell lymphoma}

Subcutaneous panniculitis-like T-cell lymphoma (SPTCL) is a rare entity which typically presents on the extremities or trunk as multiple subcutaneous nodules. ${ }^{3,28}$ It shows a broad age range. Nodal involvement is rare. By definition in the last he disease is now restricted to those tumours with an $\alpha / \beta$ origin. ${ }^{2}$

On histopathology, SPTCL presents as an atypical lymphoid infiltrate confined to subcutaneous fat. It simulates a panniculitis as the lymphoid cells produce rimming of the adipocytes and are usually admixed with reactive histiocytes (Figure 3). The disease may appear benign in early stages with greater cytologic atypia over time. The neoplastic cells are small to large. Tumour cell necrosis, karyorrhexis, and erythrophagocytosis may be seen. The neoplastic T cells in SPTCL have an $\alpha \beta$ TCR $(\beta F 1+)$, are CD3+ CD8+, CD56-, with a cytotoxic immunophenotype. They are EBV-negative.

SPTCL as currently described and restricted to cases with an $\alpha \beta$ T-cell phenotype - have a favorable prognosis with around $80 \%$ 5-year overall survival, which is in contrast to the dismal outcome of cases of $\gamma \delta$ derivation.. as discussed below 


\section{Gamma-delta T-cell lymphomas}

Normal gamma-delta T cells are usually double negative for CD4 and CD8, although a small subset may be CD8+, and are also negative for CD5. These cells which are thought to play a role in innate defense through the recognition of a limited panel of bacterial antigens, are equipped with a cytotoxic machinery and may acquire NK-like features (expression of CD16, CD56 and NK-cell receptors). They overall comprise less than $5 \%$ of the pool of normal T-cells and are mainly distributed in the epithelia and the splenic red pulp. ${ }^{29}$ Accordingly, lymphomas derived from $\gamma \delta$ T cells are very rare. Specifically, in the WHO classification two $\gamma \delta$ PTCL entities are recognized, namely hepatosplenic T-cell lymphoma and primary cutaneous $\gamma \delta$ T-cell lymphomas. ${ }^{5}$ A $\gamma \delta$ T-cell phenotype may be occasionally encountered occasionally in cases otherwise not fulfilling the criteria for these specifc $\gamma \delta$ entities, especially in PTCLs arising in mucosal sites. Irrespective of the classification, they usually pursue a very aggressive course.

\section{Hepatosplenic T-cell lymphoma}

Hepatosplenic T-cell lymphoma (HSTL) was first described in 1990 as a rare form of $\gamma \delta$ T-cell lymphoma with distinct clinico-pathologic features, in two young male patients with a fatal outcome. ${ }^{30}$ Most cases are of $\gamma \delta$ derivation, a mention included in the original designation of the entity, but since similar cases with a $\alpha \beta$ phenotype have been described ${ }^{31,32}$ the designation "hepatosplenic T-cell lymphoma" is now preferred. $^{2}$

The clinical features are uniform. Most patients are young individuals (median age 30s) with a male predominance. They present with systemic symptoms, hepatosplenomegaly, and thrombocytopenia in the absence of lymphadenopathy. They typically experience rapid relapse and a fatal outcome after initial complete response to chemotherapy.

The lymphoma cells are monomorphic, small to medium sized with moderately abundant pale cytoplasm and display sinuosidal infiltration in the spleen, liver, and sinusal localization in the bone marrow (Figure 4). The typical phenotype is $\mathrm{CD} 2+\mathrm{CD} 3+$, CD5-, usually CD4-/CD8- or sometimes CD8+, with a non-activated 
cytotoxic phenotype (TIA1+, granzyme B-, perforin-) and frequent expression of CD56 (Figure 3B). ${ }^{33,34}$ The TCR/CD3 complex is expressed at lower levels than in normal $\gamma \delta$ T cells. ${ }^{35}$

At the genetic level, HSTL is associated in most cases with isochromosome $7 q$, but how this aberration is related to the pathogenesis of the disease is unkown. ${ }^{36}$ HSTL is typically not associated with EBV. The gene expression signature of HSTL is rather homogeneous and distinct from that of non-hepatosplenic $\gamma \delta \mathrm{T}$ cell lymphomas. ${ }^{37}$

Interestingly, up to $20 \%$ of HSTL have been reported to arise in the setting of immune immune impairment, as a late post-transplantation lymhpoproliferative disorder, in the context of prolonged antigenic stimulation, and in pediatric patients with Crohn's disease under azathioprin and anti-TNF $\alpha$ therapy. ${ }^{38-40}$

\section{Primary cutaneous gamma-delta T-cell lymphoma}

Primary cutaneous $\gamma \delta$ T-cell lymphoma has been introduced as a provisional entity in the 2008 WHO classification. This rare entity comprises a subset of the cases previously diagnosed as SPTCL. ${ }^{3,28}$ Indeed, recent data have shown that the T-cell lineage $-\alpha \beta$ versus $\gamma \delta$ - was an important determinant of clinical outcome in these neoplasms. ${ }^{3,41}$ Those of $\gamma \delta$ derivation usually pursue an aggressive clinical course (20\% 5-year survival) and show frequent association with hemophagocytic syndrome, most likely secondary to cytokine production by neoplastic cells.

Lymphomatous involvement of the subcutaneous fat simulating a panniculitis, similar to what is typically observed in SPTCL, is a characteristic features. Tumour cell necrosis, karyorrhexis, and erythrophagocytosis are frequent (Figure 5). Whereas the infiltrates in SPTCL are typically limited to the subutis, in contrast cutaneous $\gamma \delta$ T-cell lymphomas frequently also display both an epidermal and dermal infiltration. ${ }^{3,}$ 42

In line with their $\gamma \delta$ T-cell derivation, the lymphoma are usually CD4- CD8This immunophenotype is also distinct from that of SPTCL (CD3+ CD8+, CD56-, $\beta \mathrm{F} 1+)$.

It has been proposed that these cutaneous $\gamma \delta \mathrm{T}$ cell lymphoma with panniculitis-like changes may be part of the spectrum of "mucocutaneous $\gamma \delta$ T cell 
lymphoma", which can be observed in different mucosae such as the nasopharynx, gastrointestinal tract or thyroid. ${ }^{43}$

\section{Enteropathy-associated T-cell Iymphoma}

Enteropathy-associated T-cell lymphoma (ETL) defines an intestinal tumor derived from intestinal intraepithelial lymphocytes (IEL). ETL mainly arises in the small intestines, frequently presents as one or more ulcerated jejunal lesions that commonly cause intestinal perforation. ETL patients have a very dismal prognosis. ${ }^{44,45}$ ETL comprises two types of diseases: type I ETL associated with celiac disease, and type II ETL, unrelated to celiac disease.

\section{ETL type I}

ETL type I occurs as a complication of gluten-sensitive enteropathy (celiac disease), and is more common in geographic regions with a higher prevalence of celiac disease such as Nordic European countries. ETL arises in the setting of long-standing celiac disease in a minority of patients at variable intervals after the initial diagnosis; in many instances ETL is diagnosed in patients with a short history of digestive complaints or represents the first manifestation of enteropathy in patients with asymptomatic villous atrophy. In the majority of cases, patients with type I ETL have celiac-disease HLA haplotypes (HLA-DQ2/8). ${ }^{46}$

ETL type I usually comprises a non-monomorphic population of lymphoid cells of various sizes ranging from small to large immunoblastic or even anaplastic cells. A predominant proportion of larger cells is often seen. Necrosis is common and the majority of tumors contain inflammatory cells (Figure 6A-6B). The adjacent nontumor mucosa shows enteropathic features, i.e. typically an increase of IEL with or without villous atrophy. However, these features may be lacking, especially when the patient is on a gluten-free diet or when the tumour occurs in the distal small intestine. ETL is not associated with EBV. The neoplastic cells express the mucosal homing receptor CD103 characteristic of intra-epithelial lymphocytes, are usually CD3+ CD5- CD4- CD8- $\alpha \beta$ T cells with an activated cytotoxic profile. CD30 is often partially expressed by the neoplastic cell population. ${ }^{2}$ 
The pathogenesis of ETL type I is closely related to that of celiac disease involving increasing numbers and activation of IEL (reviewed in ${ }^{47}$ ). In patients with symptomatic celiac disease, the development of ETL may be preceded by recurrence of clinical and pathological symptoms, so-called refractory celiac disease. In this setting, IEL acquire an abnormal immunophenotype (loss of CD8 expression and downregulation of the TCR/CD3) and show monoclonal TCR gene rearrangement. In view that an identical T-cell clone has been demonstrated in paired samples with subsequent lymphomas, refractory celiac disease with these features is thus considered as "in situ" or " intraepithelial" ETL. ${ }^{48,49} 50$ In refractory celiac disease, the monoclonal aberrant IEL are in fact multifocal or disseminated along the gastrointestinal mucosa. ${ }^{51}$ Chronic ulcerative jejunitis is another complications of celiac disease, closely related to refractory celiac disease and ETL. It is characterized by multifocal ulcerative lesions corresponding microscopically to small clonal pproliferations - "microlymphomas" - in association with aberrant IEL which are mainly distributed in the vicinity of the lesions. ${ }^{48,52}$

Interleukin-15 (IL-15), a proinflammatory cytokine upregulated in the epithelium of patients with celiac disease, is thought to play a major role in promoting the malignant transformation of IEL, by triggering an antiapoptotic pathway in IEL. ${ }^{53}$ ${ }^{54}$ At the genomic level, complex chromosomal gains at 9q31.3-qter or deletions of $16 \mathrm{q} 21.1$ are found in the majority of the cases, but gains or partial trisomy of 1q22-44 might be more specific. Gains at $5 \mathrm{q}$ are also frequent. ${ }^{55-57}$

\section{ETL type II}

A subset of so-called ETL, appears to be unrelated to celiac disease. They overall comprise a minority of ETL, but represent the major ETL type in countries where celiac disease is not prevalent. The pathological features of these ETL qualified as type II, are also distinct from those of the classical type. Histologically, ETL type II comprises a monomorphic proliferation of medium-sized cells, usually has no or little necrosis, and few admixed inflammatory cells (Figure 6C-6D). By immunophenotyping the neoplastic cells have a CD8+, CD56+ activated cytotoxic immunophenotype, and increased IEL with a similar immunophenotype may be found in the adjacent mucosa. ${ }^{58}$ The genetic profile of ETL type II partly overlaps with that 
of type I, since 9q gains and 16q deletions are also common in type II ETL. In addition, type II ETL commonly has gains of the MYC oncogene locus at $8 \mathrm{q} 24 .^{57}$

\section{PRIMARILY NODAL PTCL ENTITIES}

Four PTCL entities account for the majority of PTCL cases with nodal presentation : angioimmunoblastic T-cell lymphoma (AITL) ; anaplastic large cell lymphoma (ALCL), ALK-positive ; ALCL, ALK-negative ; and peripheral T-cell lymphoma, not otherwise specified (PTCL, NOS). AITL has distinctive pathological features. ALKpositive and ALK-negative ALCL previously viewed as two variants of the same disease entity, are now considered as as distinct disease entities. ${ }^{2}$ PTCL, NOS is an exclusion diagnosis for cases not fulfilling the criteria for any of the « specific » PTCL types.

\section{A. Angioimmunoblastic T-cell lymphoma}

AITL, the second most common PTCL wordwide, is mostly prevalent in Europe and North America where it accounts for $25-30 \%$ of the cases. ${ }^{1}$ The disease which affects elderly adults ${ }^{59}$ is usually characterized by generalized peripheral lymphadenopathy, often with concomitant extranodal disease. It is typically manifested by systemic symptoms (fever, weight loss, skin rash, arthralgias...), and by laboratory testing polyclonal hypergammaglobulinemia and Coombs-positive hemolytic anemia are frequent. Occasional spontaneous remissions are reported. The median survival is $<3$ years in most studies, but a subset of patients experience long-term survival. ${ }^{59}$

Characteristic AITL histopathologic features include capsular and perinodal infiltration sparing the peripheral cortical sinus, and prominent arborizing high endothelial veinules (Figure 7A). Three architectural patterns of lymph node involvement are recognized: pattern I, AITL with hyperplastic follicles, seen least frequently; pattern II (AITL with depleted follicles) comprising occasional regressive follicles; and pattern III (AITL without follicles), by far the most frequent, characterized by complete loss of architecture, and prominent irregular perivascular proliferation of FDCs (Figure 7B). ${ }^{60} 61$ These patterns are thought to reflect morphologic evolution of the disease rather than clinical progression ${ }^{60,61,62,63}$ The lymphoma cells are medium-sized with round or slightly irregular nuclei, clear cytoplasm and distinct cell membranes (Figure 7C). They are often 
less abundant than the admixed polymorphous reactive infiltrate of small lymphocytes, histiocytes or epithelioid cells, eosinophils and plasma cells. Large B-cell blasts, sometimes resembling Hodgkin or Reed-Sternberg cells, are almost constantly present, usually but not always infected by EBV, usually scattered throughout the tissues, sometimes numerous (B-cell-rich AITL). The abundance of B cells, which does not seem to impact the clinical outcome. ${ }^{59,64}$, correlates with the detection of B-cell clonality or oligoclonality ${ }^{65,66}$ A subset of patients go on to develop an EBV-associated B-cell lymphoproliferation, in most instances an EBV-positive diffuse large B-cell lymphoma, less commonly an EBV-negative B-cell or plasma cell neoplasms. ${ }^{62,67,68}$ AITL cases with a high content of epithelioid cells (epithelioid variant of AITL), raise differential diagnosis issues as they can suggest a granulomatous disease or be mistaken for other histiocyte-rich B- and Tcell lymphomas or Hodgkin lymphoma. ${ }^{69}$

The neoplastic cells of AITL consist of mature $\alpha \beta$ CD4+CD8- T-cells. ${ }^{70-73}$ Reduced or absent expression of pan-T-cell antigen(s) (most commonly sCD3, CD4, CD7) is frequently observed. Partial expression of CD30 by the neoplastic cells is not unusual. ${ }^{73}$ In the majority of cases, coexpression of CD10 is observed in a variable proportion of the neoplastic cells $59,61,73,74$

AITL has been recently characterized as a neoplasm derived from follicular helper T cells (TFH cells), a peculiar subset of CD4+ T cells normally found in reactive germinal centers where they provide functional help to B-cells. ${ }^{4,11,75}$ Accordingly, AITL neoplastic cells can be recognized by the expression of several markers of the follicular helper T cells $\left(\mathrm{T}_{\mathrm{FH}}\right)$, including CXCL13 (a cytoplasmic chemokine), PD1 (a member of the CD28 costimulatory receptor family resulting in negative regulation of T-cell activity), ICOS (a CD28 homologue with costimulatory function in T-cell activation and expansion) or BCL6 (Figure 7D). ${ }^{63,76,77,78,79,80-85}$. Moreover, the cellular derivation of AITL from TFH cells likely provides a rational model to explain several of the peculiar pathological and biological features inherent to this disease (Figure 8), i.e. the expansion of B cells, the intimate association with germinal centers in early disease stages and the striking proliferation of FDCs. CXCL13 is probably a major molecular mediator (for review, ${ }^{86}$ ). This chemokine critical in B-cell recruitment into germinal centers and for B-cell activation, likely promotes B-cell expansion, plasmacytic differentiation and hypergammaglobulinemia. 
The molecular alterations underlying the neoplastic transformation of TFH cells remain unknown (reviewed in ${ }^{87}$ ). By cytogenetic analysis clonal aberrations most commonly trisomies of chromosomes 3, 5 and 21, gain of $X$, and loss of $6 q$ - are detected in up to $90 \%$ of the cases (reviewed in ${ }^{88}$ ). Chromosomal breakpoints affecting the T-cell receptor (TCR) gene loci appear to be extremely rare. ${ }^{89}$

\section{B. Anaplastic large cell lymphoma, ALK-positive}

ALK-positive ALCL is a PTCL entity genetically defined by rearrangement of the $A L K$ gene on chromosome 2p23. A variety of translocations involving $A L K$ have been reported (Table 3). The most common is the $\mathrm{t}(2 ; 5)(\mathrm{p} 23 ; \mathrm{q} 35)$, which fuses the $A L K$ to the nucleophosmin gene (NPM) on chromosome 5. All translocations juxtapose the cytoplasmic catalytic domain of ALK to a partner protein, forming a chimeric fusion protein which induces constitutive ALK tyrosine kinase activation (reviewed in ${ }^{90,91}$ ). The type of translocation determines the subcellular distribution of upregulated ALK (Table 3).

ALK+ ALCL preferentially affects children and young adults. It usually presents with lymphadenopathy, but involvement of extranodal sites including the skin, bone and soft tissues is frequent. Systemic symptoms are common, especially fever. More than half of the patients present with stage III or IV disease. Overall, patients with ALK-positive ALCL have a good response to therapy and good prognosis. $^{92}$

The morphology is variable. The common pattern ( $75 \%$ of the cases) comprises sheets of large cells, showing a cohesive growth pattern and sinusoidal involvement in lymph nodes, with numerous « hallmark cells » typical of ALCL, characterized by an eccentric horseshoe-shaped nucleus and a prominent eosinophilic golgi region (Figure 9A). In the small cell pattern (5-10\% of the cases), the neoplastic population comprises small lymphoid cells with irregular nuclei, and fewer larger hallmark cells, which tend to cluster around vessels. In the lymphohistiocytic pattern (10\% of the cases), the neoplastic cells are scattered within a predominant population of reactive histiocytes. More than one pattern may be seen in one biopsy (mixed patterns), and relapses may reveal morphologic features different from those seen initially.

In addition to expression of CD30 and ALK (Figure 9B), the vast majority of 
cases are also positive for EMA. The tumor cells exhibit an aberrant T-cell immunophenotype with defective expression of the TCR/CD3 complex and of many T-cell antigens, despite a T-cell genotype. ${ }^{65,93-95}$ CD2, CD4 and CD45 are the msot frequently preserved antigens. Most cases express cytotoxic-associated antigens (TIA1, granzymeB, perforin) suggesting derivation from activated cytotoxic T cells.

In vitro, constitutively activated ALK chimeras induce cellular transformation, enhance cell proliferation and survival (for review, see ${ }^{91,96}$ ). The oncogenic proprties of ALK are mediated by interaction with downstream molecules that engage intracellular signalling pathways, among which the JAK3-STAT3 pathway is of prime importance, as exemplified by the fact that in ALCL cell lines, two thirds of ALKregulated genes are concordantly dependent on STAT3 expression. ${ }^{97}$ The transcription factor C/EBPbeta which is part of the molecular signature os ALK-positive ALCL, also plays an important role as it is absolutely necessary to induce cell transformation and/or to sustain the growth and survival of ALK-positive ALCL cells. ${ }^{98,99}$ In vivo, however, the NPM-ALK fusion transcript has been detected at low levels in reactive lymph node and normal peripheral blood samples of healthy individuals, suggesting additional cofactors. ${ }^{100,101}$ Accordingly, secondary genetic alterations are common in ALK+ ALCL, and specifically, gain of 17p (including a gain of TP53, but with no apparent correlation with protein expression) and loss of $4 \mathrm{q}$ seem to be the most characteristic. ${ }^{102}$ No etiologic agent has been linked to ALCL but interestingly, there have been case reports of systemic ALK-positive ALCL presenting at onset with skin lesions occurring after an insect bite, suggesting a direct relationship, and the possibility that inflammatory mediators released upon the bite might represent a second hit eliciting lymphoma development. ${ }^{103}$

\section{Anaplastic large cell lymphoma, ALK-negative}

ALK-negative ALCL introduced in the 2008 WHO classification as a provisional entity, is defined as a large cell lymphoma with comparable morphology to the common pattern of ALK-positive ALCL, with uniformly strong CD30 expression and lack of ALK expression (Figure 9C-9D). ${ }^{2}$ Compared to ALK-positive ALCL, ALKnegative tumors have more preserved expression of T-cell antigens while the expression of cytotoxic markers and of EMA tends to be less frequent. ${ }^{104}$ ALK- 
negative ALCL may be difficult to distinguish from PTCL, NOS, since a subset of the latter may exhibit large cell morphology and/or strong CD30 expression.

ALK-negative ALCL tends to occur in older individuals, with less frequent extranodal involvement. The clinical course and prognosis of the patients are worse than for those with ALK-positive tumors, but more favorable than for PTCL, NOS patients. $^{92,104}$

ALK-negative ALCL is postulated to derive from an activated cytotoxic T cell, but the oncogenic alterations are unknown. There is no association with EBV infection. Chromosomal aberrations are detected by genomic profiling in about two thirds of the cases which differ from those of ALK-positive ALCL. ${ }^{102}$ While distinct signatures have been derived from the comparison of ALK+ and ALK- ALCL. ${ }^{99}$, transcriptional profiling studies have also evidenced much commonality between the two ALCL entities, irrespective of ALK expression, ${ }^{97}$ and have not provided a meaningful insight into the pathogenesis of ALK-negative ALCL. The presence of extracopies of the $P A X-5$ gene in a subset of ALCL, might represent an alteration relevant to lymphomagenesis. ${ }^{105}$

Interestingly, there have been recent reports of primary extranodal ALKnegative ALCL occurring in the vicinity of breast implants, presenting with seromas, infrequent tumor masses and no evidence of distant tumor dissemination. These breast ALCLs have an overall indolent clinical behaviour, perhaps akin to that of primary cutaneous ALCL. ${ }^{106-109}$

\section{Peripheral T Cell Lymphoma, not otherwise specified (PTCL, NOS)}

PTCL, NOS, the most common and also most heterogeneous category of PTCL, is defined by default for cases not fulfilling the criteria for more «specific » entities. Presentation is usually nodal but any site may be affected and extranodal involvement is common. The median age of patients is in the seventh decade, and $65 \%$ of the patients have stage IV disease. Blood eosinophilia, pruritis and hemophagocytic syndromes may occur. The clinical course usually comprises frequent relapses, and patients pursue an overall poor outcome (20-30\% 5-year survival). ${ }^{110}$

PTCL, NOS typically contain a mixture of small and large atypical cells. The presence of cells with clear cytoplasm, increased vascularization and eosinophilia are 
frequent features (Figure 10). T-cell-associated antigens are variably expressed with frequent loss of CD7, more rarely CD3, CD5 and/or CD2. Most cases are CD4+CD8-. EBV has been recorded in up to $50 \%$ of the cases in bystander B cells and/or a variable fraction of the tumor cells and this finding is correlated with a worse survival. $^{111,112}$

Several variants have been described, but without clear translation into distinct clinico-pathological entities. The lymphoepithelioid variant of PTCL, NOS (Lennert's lymphoma) has a characteristic background made up of numerous epithelioid histiocytes and consists of atypical small cytotoxic T-cells, most commonly CD8positive. ${ }^{113}$ Compared to other PTCL, NOS, the lymphoepithelioid variant tends to remain confined to lymph nodes with infrequent extranodal involvement ${ }^{114}$, and may be associated with an overall better prognosis. The follicular variant of PTCL, NOS named after a pattern of growth intimately related to follicular structures, has been recently described. It comprises cases with a truly follicular pattern, mimicking follicular lymphoma, ${ }^{115}$ T-cell lymphomas with a perifollicular growth pattern, ${ }^{116}$ or involving expanded mantle zones. ${ }^{117,118}$ In view of the $\mathrm{T}_{\mathrm{FH}}$ phenotype and overlapping features with AITL in some cases, the possible relationship to AITL is questionable. ${ }^{115,118,119}$ A recurrent chromosomal translocation $t(5 ; 9)(q 33 ; q 22)$ involving ITK and SYK tyrosine kinase, has been described in association with follicular PTCLs, ${ }^{120}$ but is otherwise rarely found in non-follicular PTCLs, which may support the concept of a distinct subtype. Interestingly, however, overexpression and activation of SYK appear to be a feature common to most PTCLs, which potentially represents a novel therapeutic target. ${ }^{121,122}$

Attempts to subclassify PTCL-NOS according to immunological features (CD4 versus CD8 subsets, Th1 versus Th2 helper function, differentiation stage) have overall not proven meaningful. ${ }^{123,124}$ At the molecular level, PTCLs, NOS are most closely related to activated than resting CD4 or CD8+ T cells, and are characterized by deregulation of genes related to proliferation, apoptosis, cell adhesion, matrix remodeling. ${ }^{10}$ Interestingly, some cases classified as PTCL, NOS based on their pathological features, have been found to harbor imprints of traces of the $\mathrm{T}_{\mathrm{FH}}$ signature, NOS, suggesting that a subset of PTCL, NOS might be related to AITL, and/or that the AITL spectrum might be wider than suspected. ${ }^{125}$ Iqbal et al. identified a molecular subgroup with features of cytotoxic $\mathrm{T}$ lymphocytes and a poor survival compared with other PTCL, NOS cases ${ }^{126}$, and accordingly expression of 
cytotoxic molecules in PTCL, NOS has been found in association with clinical features indicative of a poorer prognosis. ${ }^{127}$

PTCLs, NOS frequently harbor complex karyotypes, and their genomic imbalances differ from those observed in AITL and ALCL. ${ }^{128-130}$ Oncogenic alterations are poorly characterized. Gene expression profiling identified the PDGFRalpha as a potential novel therapeutic target in PTCL, NOS, as it is overexpressed and activated in most cases. ${ }^{10,131}$ Overexpression of NF-kappaB pathway genes was found in one study to correlate with a better outcome. ${ }^{8}$ Conversely, overexpression of a proliferation signature correlated with an adverse prognosis, and appears to be inversely related to signature clusters related to inflammatory response and reflective of an abundant reactive background in the tumor. $^{9,} 12$

\section{CONCLUDING REMARKS}

Novel insights to the pathobiology of PTCLs have been gained over the past few years, stemming from epidemiological studies, clinico-pathological analyses and high-throughput molecular profiling studies. Significantly, the demonstration of hte cellular derivation of AITL from TFH cells represents a major step in the understanding of the biology this disease entity, and may also potentially open the way to the development of targeted therapies. Whether evidence for a TFH derivation would become a specific defining feature for this entity remains to be determined, but it is likely that the spectrum of AITL will expand. Yet, the large group of PTCL without specification remains poorly understoood and the clinical relevance of subgroups identified within that large entity has to be clarified. 
TABLE 1. Mature T- and NK-cell neoplasms in the 2008 WHO classification of lymphoid tumors (adapted from ${ }^{2}$ )

\section{$\underline{\text { Leukemic or disseminated }}$}

T-cell prolymphocytic leukemia

T-cell large granular lymphocytic leukemia

Chronic lymphoproliferative disorders of NK cells*

Aggressive NK-cell leukemia

Adult T-cell lymphoma/leukemia (HTLV1-positive)

Systemic EBV-positive T-cell lymphoproliferative disorders of childhood

\section{Extranodal}

Extranodal NK/T-cell lymphoma, nasal type

Enteropathy-associated T-cell lymphoma

Hepatosplenic T-cell lymphoma

\section{Cutaneous}

Mycosis fungoides

Sezary syndrome

Primary cutaneous CD30+ lymphoproliferative disorders

Primary cutaneous anaplastic large cell lymphoma

Lymphomatoid papulosis

Subcutaneous panniculitis-like T-cell lymphoma

Primary cutaneous gamma-delta T-cell lymphoma*

Primary cutaneous aggressive epidermotropic CD8+ cytotoxic T-cell lymphoma*

Primary cutaneous small/medium CD4+ T-cell lymphoma*

Hydroa vacciniforme-like lymphoma

\section{Nodal}

Angioimmunoblastic T-cell lymphoma (AITL)

Anaplastic large cell lymphoma, ALK-positive

Anaplastic large cell lymphoma, ALK-negative*

Peripheral T-cell lymphoma, not otherwise specified (PTCL, NOS)

* designates provisional entities 
TABLE 2. Frequency of the most common PTCL entities (adapted from ${ }^{6}$ )

Peripheral T-cell lymphoma, not otherwise specified (PTCL, NOS) 26\%

Angioimmunoblastic T-cell lymphoma (AITL) $18 \%$

Extranodal NK/T-cell lymphoma, nasal type $\quad 10 \%$

Adult T-cell lymphoma/leukemia (HTLV1-positive) $10 \%$

Anaplastic large cell lymphoma, ALK-positive $\quad 7 \%$

Anaplastic large cell lymphoma, ALK-negative $\quad 5 \%$

Enteropathy-associated T-cell lymphoma $\quad 5 \%$

Primary cutaneous anaplastic large cell lymphoma $\quad 2 \%$

$\begin{array}{ll}\text { Hepatosplenic T-cell lymphoma } & 1 \%\end{array}$

Subcutaneous panniculitis-like T-cell lymphoma $\quad 1 \%$

$\begin{array}{ll}\text { Other entities and unclassifiable cases } & 14 \%\end{array}$ 
TABLE 3. Translocations and fusion proteins in ALK-positive ALCL

\begin{tabular}{l|l|c|l} 
Translocation & \multicolumn{1}{|c|}{ Partner gene } & Frequency & \multicolumn{1}{|c}{ ALK staining pattern } \\
\hline $\mathbf{t}(\mathbf{2} ; \mathbf{5})$ & Nucleophosmin (NPM) & $75 \%$ & $\begin{array}{l}\text { Cytoplasmic + nuclear + } \\
\text { nucleolar }\end{array}$ \\
\hline $\mathbf{t}(\mathbf{1 ; 2})$ & Tropomyosin 3 (TPM3) & $10-20 \%$ & Cytoplasmic \\
\hline $\mathbf{t}(\mathbf{2 ; 3 )}$ & TRK fused gene (TFG) & $2-5 \%$ & Cytoplasmic \\
\hline $\mathbf{i n v}(\mathbf{2})$ & ATIC (Pur H gene) & $2-5 \%$ & Cytoplasmic \\
\hline $\mathbf{t}(\mathbf{2} ; \mathbf{1 7})$ & Clathrin heavy chain (CLTC) & $2-5 \%$ & Cytoplasmic/granular \\
\hline $\mathbf{t}(\mathbf{2} ; \mathbf{2 2})$ & Myosin heavy chain (MYH9) & rare & Cytoplasmic \\
\hline $\mathbf{t}(\mathbf{2} ; \mathbf{1 7})$ & $\begin{array}{l}\text { ALK lymphoma } \\
\text { oligomerization partner on } \\
\text { chromosome 17 (ALO17) }\end{array}$ & rare & Cytoplasmic \\
\hline $\mathbf{t}(\mathbf{2} ; \mathbf{1 9})$ & Tropomyosin 4 (TPM4) & rare & Cytoplasmic \\
\hline $\mathbf{t}(\mathbf{2} ; \mathbf{X})$ & Moesin (MSN) & rare & Membrane-associated \\
\hline
\end{tabular}




\section{LEGENDS FOR FIGURES}

Figure 1. Overview of T-cell and NK-cell differentiation and the putative histogenetic derivation of the major subtypes of mature T and NK-cell neoplasms.

Based on the structure of the TCR, two classes of T cells are recognized: $\alpha \beta$ and $\gamma \delta$; both express CD3. Gamma-delta T cells are CD4-CD8- or less often CD4-CD8+, they comprise $<5 \%$ of $\mathrm{T}$ cells in the peripheral blood and show a restricted distribution mainly to the epithelia where they are involved in mucosal immunity, and to the red pulp of the spleen. Alpha-beta T cells are divided into CD4+ (mainly helper, with Th1 or Th2 profile of cytokine-secretion) and CD8+ (mainly cytotoxic) subsets. Mature naive $\mathrm{T}$ cells, are found in the thymic medulla, in the circulation and in the paracortex of lymph nodes. Antigen-dependent reaction occurs in the paracortex of lymph nodes. From the immunoblastic reaction come antigen-specific T cells of either CD4 or CD8 type, as well as memory cells, that may recirculate and home to peripheral tissues.

NK cells lack TCR rearrangement and membrane TCR expression. NK cells share some markers with T-cells as they can express CD2, CD7, CD43, CD45RO, and cytoplasmic (but not surface) CD3. NK cells are usually CD4-CD8- but may be $\mathrm{CD} 8+$, and they express one or several of the «NK-associated » antigens (CD11b, CD16, CD56, CD57, NK receptors), none of which, except maybe CD16 is specific since they can also be expressed by some T cells. Both NK cells and activated cytotoxic T cells express cytotoxic proteins, T-cell intracellular antigen (TIA)-1, perforin, and granzymeB.

Functionally, the majority of $\mathrm{T}$ cells are part of the specific/adaptative immune system and recognize the antigen in a MHC-restricted fashion in the presence of an antigen-presenting cell, whereas NK cells, a subset of the $\gamma \delta \mathrm{T}$ cells and a minor subset of $\alpha \beta$ T cells are part of the innate immunity, i.e. the recognition of antigens occurs through surface receptors independently of a MHC-restricted presentation, involving NK receptors and toll-like receptors.

Mature T/NK-cell lymphomas manifest the immunophenotypic and genetic features of post-tymic T lymphocytes or mature NK cells. NK give rise to NK-cell lymphomas in tissues, usually in the nasal area. Many extranodal T-cell lymphomas derive from cytotoxic T cells; one exception is mycosis fungoides derived from 
effector CD4+ cells with cutaneous homing properties. $\gamma \delta \mathrm{T}$ cells give rise to most cases of hepatosplenic T-cell lymphomas as well as a subset of cutaneous T-cell lymphomas. Enteropathy-associated T-cell lymphoma derives from intraepithelial usually $\alpha \beta-\mathrm{T}$ cells of the intestine. Adult T-cell lymphoma/leukemia associated with HTLV1 infection, is a neoplasm derived from a subset of CD4+ T cells with a frequent regulatory phenotype (CD25+ FoxP3+). The cellular derivation of AITL from CD4+ helper T cells in germinal centers has been recently established. ALCL are postulated to derive rom cytotoxic T cells while hte majority of PTCL, NOS appear to derive from activated CD4+ T cells.

Abbreviations : AITL : angioimmunoblastic T-cell lymphoma ; ALCL : anaplastic large cell lymphoma ; PTCL, NOS: peripheral T-cell lymphoma, not otherwise specified; TCL : T-cell lymphoma.

FIGURE 2. Extranodal NK/T-cell lymphoma, nasal type

(A) Infiltrate of medium-sized atypical lymphoid cells obliterating the nasal mucosal glands ; (B) pleomorphic medium to large lymphoid cells showing angiotropism ; (C) strong expression of CD56 by the neoplastic cells ; (D) in situ hybridization for EBV showing a positive signal in most cells.

FIGURE 3. Subcutaneous panniculitis-like T-cell lymphoma (A)The infiltrate confined to the subcutaneous fat is composed of a predominance of atypical small to medium lymphoid cells which often adopt a rimming configuration around adipocytes; (B) these cells have a cytotoxic CD8+ phenotype.

FIGURE 4. Hepatosplenic T-cell lymphoma

(A) Infiltrate of the splenic red pulp, specially dilated sinuses, by neoplastic monomorphic medium-sized cells; (B) in the bone marrow, the infiltrate is confined to the sinuses

FIGURE 5. Primary cutaneous $\gamma \delta$ T-cell lymphoma

(A) Subcutaneous lymphoma infiltrate of medium to large atypical cells with rimming of the adipocytes ; (B) frozen section immunohistochemistry demonstrating of $\gamma \delta$ TCR expression by the neoplastic cells . 
FIGURE 6. Enteropathy-associated T-cell lymphoma

(A-B) Type I enteropathy-associated T-cell lymphoma comprising a population of large pleomorphic and partially anaplastic lymphoid cells, with admiwed inflammatory cells and focal necrosis ; the adjacent small intestinal mucosa shows villous atrophy and increased intraepithelial lymphocytes. (C-D) Type I enteropathyassociated T-cell lymphoma consisting of a monomorphic infiltrate of small to medium sized cells.

FIGURE 7. Anaplastic large cell lymphoma

(A) Anaplastic large cell lymphoma, ALK-positive, comprising a cohesive population of large lymphoid cells with hallmark features and in this case pleomorphic features ; (B) cytoplasmic ALK expression demonstrated by immunohistochemistry in a case with an inv(2) ; (C) ALK-negative anaplastic large cell lymphoma comprising many cells with hallmark features ; (D) strong CD30 expression in an ALK-negative ALCL case ; (E) EMA expression in an ALK-negative ALCL

FIGURE 8. Angioimmunoblastic T-cell lymphoma

(A) Low power view of a lymph node showing a type III patter of involvement, with diffuse architectural effacement and the characteristic "sinus sign"; (B) CD21 immunostainign showing irregular proliferation of follicular dendritic cells; (C) high power view of the lymphoma infiltrate comprising medium-sized atypical lymphoid cells with scatterd blasts and inflammatory cells, in association with prominent vascularity; (D) PD1 expression at variable levels by the neoplastic cells

FIGURE 9. Cellular and molecular players in angioimmunoblastic T-cell lymphoma. In AITL, a complex network of interactions take place between the tumor cells and the various cellular components of the reactive microenvironment. Different factors released by $\mathrm{T}_{\mathrm{FH}}$ cells are involved in B-cell recruitment, activation and differentiation (CXCL13), in the modulation of other T-cell subsets (IL21, IL10, TFG $\beta$ ), or in promoting vascular proliferation (VEGF, angiopoietin), and may also act as autocrine factors. CXCL13 may also attract mast cells (MC) which are a source of IL6 
promoting Th17 differentiation. EBV reactivation occurs in the context of a deregulated immune response, which also favors the expansion of both $\mathrm{T}_{\mathrm{FH}}$ cells and $\mathrm{B}$ cells. TGFb is a mediator of FDC differentiation and proliferation, and FDC in turn are a source of CXCL13 and VEGF.

B: B-cell; FDC: follicular dendritic cell; HEV: high endothelial veinule; MC: mast cell; PC: plasma cell; $\mathrm{T}_{\mathrm{FH}}$ : follicular helper $\mathrm{T}$ cell.

FIGURE 10. Peripheral T-cell lymphoma, not otherwise specified Examples of the morphologic variability of peripheral T-cell lymphoma, not otherwise specified: (A) a case with pleomorphic features and abundant eosinophilia, and (B) a case with a more monotonous tumor cell population and inconspicuous reactive cell component. 


\section{REFERENCES}

1. Rudiger T, Weisenburger DD, Anderson JR et al. Peripheral T-cell lymphoma (excluding anaplastic large-cell lymphoma): results from the Non-Hodgkin's Lymphoma Classification Project. Ann Oncol 2002 Jan;13(1);140-149.

2. Swerdlow S, Campo E, Harris N et al. WHO Classification of Tumours of Haematopoietic and Lymphoid Tissues. Lyon: IARC Press, 2008.

3. Toro JR, Liewehr DJ, Pabby $\mathrm{N}$ et al. Gamma-delta T-cell phenotype is associated with significantly decreased survival in cutaneous T-cell lymphoma. Blood 2003 May 1;101(9);3407-3412.

4. de Leval L, Rickman DS, Thielen C et al. The gene expression profile of nodal peripheral T-cell lymphoma demonstrates a molecular link between angioimmunoblastic T-cell lymphoma (AITL) and follicular helper T (TFH) cells. Blood 2007 Jun 1;109(11);4952-4963.

5. Tripodo C, Iannitto E, Florena AM et al. Gamma-delta T-cell lymphomas. Nature reviews 2009 Dec;6(12);707-717.

6. Armitage J, Vose J, Weisenburger D. International peripheral T-cell and natural killer/T-cell lymphoma study: pathology findings and clinical outcomes. $J$ Clin Oncol 2008 Sep 1;26(25);4124-4130.

7. Martinez-Delgado B, Melendez B, Cuadros M et al. Expression profiling of Tcell lymphomas differentiates peripheral and lymphoblastic lymphomas and defines survival related genes. Clin Cancer Res 2004 Aug 1;10(15);4971-4982.

8. Martinez-Delgado B, Cuadros M, Honrado E et al. Differential expression of NF-kappaB pathway genes among peripheral T-cell lymphomas. Leukemia 2005 Dec;19(12);2254-2263.

9. Ballester B, Ramuz O, Gisselbrecht $\mathrm{C}$ et al. Gene expression profiling identifies molecular subgroups among nodal peripheral T-cell lymphomas. Oncogene 2006 Mar 9;25(10);1560-1570.

10. Piccaluga PP, Agostinelli C, Califano A et al. Gene expression analysis of peripheral T cell lymphoma, unspecified, reveals distinct profiles and new potential therapeutic targets. J Clin Invest 2007 Mar;117(3);823-834.

11. Piccaluga PP, Agostinelli C, Califano A et al. Gene expression analysis of angioimmunoblastic lymphoma indicates derivation from $\mathrm{T}$ follicular helper cells and vascular endothelial growth factor deregulation. Cancer Res 2007 Nov 15;67(22);10703-10710.

12. Cuadros M, Dave SS, Jaffe ES et al. Identification of a proliferation signature related to survival in nodal peripheral T-cell lymphomas. J Clin Oncol 2007 Aug $1 ; 25(22) ; 3321-3329$.

13. Iqbal J, Kucuk C, Deleeuw RJ et al. Genomic analyses reveal global functional alterations that promote tumor growth and novel tumor suppressor genes in natural killer-cell malignancies. Leukemia 2009 Jun;23(6);1139-1151.

14. Jaffe ES, Krenacs L, Raffeld M. Classification of cytotoxic T-cell and natural killer cell lymphomas. Semin Hematol 2003 Jul;40(3);175-184.

15. Jaffe ES. Pathobiology of peripheral T-cell lymphomas. Hematology / the Education Program of the American Society of Hematology. American Society of Hematology 2006;317-322. 
16. Bossard C, Belhadj K, Reyes F et al. Expression of the granzyme B inhibitor PI9 predicts outcome in nasal NK/T-cell lymphoma : results of a Western series of 48 patients treated with first-line polychemotherapy within the Groupe d'Etude des Lymphomes de l'Adulte (GELA) trials. Blood 2006 Oct 31.

17. Cheung MM, Chan JK, Lau WH, Ngan RK, Foo WW. Early stage nasal NK/T-cell lymphoma: clinical outcome, prognostic factors, and the effect of treatment modality. Int J Radiat Oncol Biol Phys 2002 Sep 1;54(1);182-190.

18. Boulland ML, Meignin V, Leroy-Viard K et al. Human interleukin-10 expression in T/natural killer-cell lymphomas: association with anaplastic large cell lymphomas and nasal natural killer-cell lymphomas. Am J Pathol 1998;153(4);12291237.

19. Teruya-Feldstein J, Jaffe ES, Burd PR et al. The role of Mig, the monokine induced by interferon-gamma, and IP-10, the interferon-gamma-inducible protein-10, in tissue necrosis and vascular damage associated with Epstein-Barr virus-positive lymphoproliferative disease. Blood 1997 Nov 15;90(10);4099-4105.

20. Nakashima Y, Tagawa H, Suzuki R et al. Genome-wide array-based comparative genomic hybridization of natural killer cell lymphoma/leukemia: different genomic alteration patterns of aggressive NK-cell leukemia and extranodal Nk/T-cell lymphoma, nasal type. Genes Chromosomes Cancer 2005 Nov;44(3);247255.

21. Taborelli M, Tibiletti MG, Martin V, Pozzi B, Bertoni F, Capella C. Chromosome band 6q deletion pattern in malignant lymphomas. Cancer Genet Cytogenet 2006 Mar;165(2);106-113.

22. Huang Y, de Reynies A, de Leval L et al. Gene expression profiling identifies emerging oncogenic pathways operating in extranodal NK/T-cell lymphoma, nasal type. Blood 2010 Feb 11;115(6);1226-1237.

23. Coppo P, Gouilleux-Gruart V, Huang Y et al. STAT3 transcription factor is constitutively activated and is oncogenic in nasal-type NK/T-cell lymphoma. Leukemia 2009 Sep;23(9);1667-1678.

24. Quintanilla-Martinez L, Kremer M, Keller G et al. p53 Mutations in nasal natural killer/T-cell lymphoma from Mexico: association with large cell morphology and advanced disease. Am J Pathol 2001 Dec;159(6);2095-2105.

25. Takakuwa T, Dong Z, Nakatsuka S et al. Frequent mutations of Fas gene in nasal NK/T cell lymphoma. Oncogene 2002 Jul 11;21(30);4702-4705.

26. Lin CW, Chen YH, Chuang YC, Liu TY, Hsu SM. CD94 transcripts imply a better prognosis in nasal-type extranodal NK/T-cell lymphoma. Blood 2003 Oct 1;102(7);2623-2631.

27. $\mathrm{Au} \mathrm{WY}$, Weisenburger DD, Intragumtornchai $\mathrm{T}$ et al. Clinical differences between nasal and extranasal natural killer/T-cell lymphoma: a study of 136 cases from the International Peripheral T-Cell Lymphoma Project. Blood 2009 Apr 23;113(17);3931-3937.

28. Go RS, Wester SM. Immunophenotypic and molecular features, clinical outcomes, treatments, and prognostic factors associated with subcutaneous panniculitis-like T-cell lymphoma: a systematic analysis of 156 patients reported in the literature. Cancer 2004 Sep 15;101(6);1404-1413.

29. Groh V, Fabbi M, Hochstenbach F, Maziarz RT, Strominger JL. Doublenegative (CD4-CD8-) lymphocytes bearing T-cell receptor alpha and beta chains in normal human skin. Proc Natl Acad Sci U S A 1989 Jul;86(13);5059-5063. 
30. Farcet JP, Gaulard P, Marolleau JP et al. Hepatosplenic T-cell lymphoma: sinusal/sinusoidal localization of malignant cells expressing the T-cell receptor gamma delta. Blood 1990;75(11);2213-2219.

31. Suarez F, Wlodarska I, Rigal-Huguet F et al. Hepatosplenic alphabeta T-cell lymphoma: an unusual case with clinical, histologic, and cytogenetic features of gammadelta hepatosplenic T-cell lymphoma. Am J Surg Pathol 2000 Jul;24(7);10271032 .

32. Macon WR, Levy NB, Kurtin PJ et al. Hepatosplenic alphabeta T-cell lymphomas: a report of 14 cases and comparison with hepatosplenic gammadelta Tcell lymphomas. Am J Surg Pathol 2001 Mar;25(3);285-296.

33. Belhadj K, Reyes F, Farcet J-P et al. Hepatosplenic \{gamma\}\{delta\} T-cell lymphoma is a rare clinicopathologic entity with poor outcome: report on a series of 21 cases. Blood 2003 August 7, 2003;2003-2005-1675.

34. Cooke C, Greiner T, Raffeld M, Kingma D, Stetler-Stevenson M, Jaffe E. gd T-cell lymphoma: a distinct clinicopathologic entity. Mod Pathol 1994;7;106A.

35. Baseggio L, Berger F, Monneret G, Magaud JP, Salles G, Felman P. The expression of TCR-gamma delta/CD3 complex in neoplastic gamma delta T-cell. Haematologica 2006 Dec;91(12);1717-1719.

36. Wlodarska I, Martin-Garcia N, Achten R et al. Fluorescence in situ hybridization study of chromosome 7 aberrations in hepatosplenic T-cell lymphoma: isochromosome $7 \mathrm{q}$ as a common abnormality accumulating in forms with features of cytologic progression. Genes Chromosomes Cancer 2002 Mar;33(3);243-251.

37. Miyazaki K, Yamaguchi M, Imai $\mathrm{H}$ et al. Gene expression profiling of peripheral T-cell lymphoma including gammadelta T-cell lymphoma. Blood 2009 Jan 29;113(5);1071-1074.

38. Belhadj K, Reyes F, Farcet JP et al. Hepatosplenic gammadelta T-cell lymphoma is a rare clinicopathologic entity with poor outcome: report on a series of 21 patients. Blood 2003 Dec 15;102(13);4261-4269.

39. Rosh JR, Gross T, Mamula P, Griffiths A, Hyams J. Hepatosplenic T-cell lymphoma in adolescents and young adults with Crohn's disease: a cautionary tale? Inflammatory bowel diseases 2007 Aug;13(8);1024-1030.

40. Shale M, Kanfer E, Panaccione R, Ghosh S. Hepatosplenic T cell lymphoma in inflammatory bowel disease. Gut 2008 Dec;57(12);1639-1641.

41. Willemze R, Jansen PM, Cerroni L et al. Subcutaneous panniculitis-like T-cell lymphoma: definition, classification, and prognostic factors: an EORTC Cutaneous Lymphoma Group Study of 83 cases. Blood 2008 Jan 15;111(2);838-845.

42. Toro JR, Beaty M, Sorbara L et al. gamma delta T-cell lymphoma of the skin: a clinical, microscopic, and molecular study. Arch Dermatol 2000 Aug;136(8);10241032.

43. Arnulf B, Copie-Bergman C, Delfau-Larue M-H et al. Nonhepatosplenic gd T-cell lymphoma: a subset of cytotoxic lymphomas with mucosal or skin localization. Blood 1998;91;1723-1731.

44. Wohrer S, Chott A, Drach J et al. Chemotherapy with cyclophosphamide, doxorubicin, etoposide, vincristine and prednisone (CHOEP) is not effective in patients with enteropathy-type intestinal T-cell lymphoma. Ann Oncol 2004 Nov;15(11);1680-1683.

45. Ferreri AJ, Zinzani PL, Govi S, Pileri SA. Enteropathy-associated T-cell lymphoma. Critical reviews in oncology/hematology Jul 22.

46. Howell WM, Leung ST, Jones DB et al. HLA-DRB, -DQA, and-DQB polymorphism in celiac disease and enteropathy- associated T-cell lymphoma. 
Common features and additional risk factors for malignancy. Hum Immunol 1995;43(1);29-37.

47. van de Water JM, Cillessen SA, Visser OJ, Verbeek WH, Meijer CJ, Mulder CJ. Enteropathy associated T-cell lymphoma and its precursor lesions. Best practice \& research Feb;24(1);43-56.

48. Ashton-Key M, Diss TC, Pan L, Du MQ, Isaacson PG. Molecular analysis of T-cell clonality in ulcerative jejunitis and enteropathy-associated T-cell lymphoma. Am J Pathol 1997 Aug;151(2);493-498.

49. Cellier C, Delabesse E, Helmer C et al. Refractory sprue, coeliac disease, and enteropathy-associated T-cell lymphoma. French Coeliac Disease Study Group.

Lancet 2000 Jul 15;356(9225);203-208.

50. Isaacson PG. Relation between cryptic intestinal lymphoma and refractory sprue. Lancet 2000 Jul 15;356(9225);178-179.

51. Cellier C, Patey N, Mauvieux L et al. Abnormal intestinal intraepithelial lymphocytes in refractory sprue. Gastroenterology 1998 Mar;114(3);471-481.

52. Verbeek WH, Goerres MS, von Blomberg BM et al. Flow cytometric determination of aberrant intra-epithelial lymphocytes predicts T-cell lymphoma development more accurately than T-cell clonality analysis in Refractory Celiac Disease. Clinical immunology (Orlando, Fla 2008 Jan;126(1);48-56.

53. Mention JJ, Ben Ahmed M, Begue B et al. Interleukin 15: a key to disrupted intraepithelial lymphocyte homeostasis and lymphomagenesis in celiac disease.

Gastroenterology 2003 Sep;125(3);730-745.

54. Malamut G, El Machhour R, Montcuquet N et al. IL-15 triggers an antiapoptotic pathway in human intraepithelial lymphocytes that is a potential new target in celiac disease-associated inflammation and lymphomagenesis. J Clin Invest Jun $1 ; \mathbf{1 2 0}(6) ; 2131-2143$.

55. Zettl A, Ott G, Makulik A et al. Chromosomal gains at 9q characterize enteropathy-type T-cell lymphoma. Am J Pathol 2002 Nov;161(5);1635-1645.

56. Verkarre V, Romana SP, Cellier C et al. Recurrent partial trisomy 1q22-q44 in clonal intraepithelial lymphocytes in refractory celiac sprue. Gastroenterology 2003 Jul;125(1);40-46.

57. Deleeuw RJ, Zettl A, Klinker E et al. Whole-genome analysis and HLA genotyping of enteropathy-type T-cell lymphoma reveals 2 distinct lymphoma subtypes. Gastroenterology 2007 May;132(5);1902-1911.

58. Chott A, Haedicke W, Mosberger I et al. Most CD56+ intestinal lymphomas are CD8+CD5-T-cell lymphomas of monomorphic small to medium size histology. Am J Pathol 1998 Nov;153(5);1483-1490.

59. Mourad N, Mounier N, Briere J et al. Clinical, biologic, and pathologic features in 157 patients with angioimmunoblastic T-cell lymphoma treated within the Groupe d'Etude des Lymphomes de l'Adulte (GELA) trials. Blood 2008 May $1 ; \mathbf{1 1 1}(9) ; 4463-4470$.

60. Ree HJ, Kadin ME, Kikuchi M et al. Angioimmunoblastic lymphoma (AILDtype T-cell lymphoma) with hyperplastic germinal centers. Am J Surg Pathol 1998;22(6);643-655.

61. Attygalle A, Al-Jehani R, Diss TC et al. Neoplastic T cells in angioimmunoblastic T-cell lymphoma express CD10. Blood 2002 Jan 15;99(2);627633.

62. Attygalle AD, Kyriakou C, Dupuis J et al. Histologic evolution of angioimmunoblastic T-cell lymphoma in consecutive biopsies: clinical correlation and 
insights into natural history and disease progression. Am J Surg Pathol 2007 Jul;31(7);1077-1088.

63. Rodriguez-Justo M, Attygalle AD, Munson P, Roncador G, Marafioti T, Piris MA. Angioimmunoblastic T-cell lymphoma with hyperplastic germinal centres: a neoplasia with origin in the outer zone of the germinal centre? Clinicopathological and immunohistochemical study of 10 cases with follicular T-cell markers. Mod Pathol 2009 Jun;22(6);753-761.

64. Lome-Maldonado C, Canioni D, Hermine O et al. Angio-immunoblastic T cell lymphoma (AILD-TL) rich in large B cells and associated with Epstein-Barr virus infection. A different subtype of AILD-TL? Leukemia 2002 Oct;16(10);2134-2141. 65. Bruggemann $\mathrm{M}$, White $\mathrm{H}$, Gaulard $\mathrm{P}$ et al. Powerful strategy for polymerase chain reaction-based clonality assessment in T-cell malignancies Report of the BIOMED-2 Concerted Action BHM4 CT98-3936. Leukemia 2007 Feb;21(2);215221.

66. Brauninger A, Spieker T, Willenbrock K et al. Survival and clonal expansion of mutating "forbidden" (immunoglobulin receptor-deficient) Epstein-Barr virusinfected B cells in angioimmunoblastic T-cell lymphoma. J Exp Med 2001 Oct $1 ; \mathbf{1 9 4}(7) ; 927-940$.

67. Zettl A, Lee SS, Rudiger T et al. Epstein-Barr virus-associated B-cell lymphoproliferative disorders in angloimmunoblastic T-cell lymphoma and peripheral T-cell lymphoma, unspecified. Am J Clin Pathol 2002 Mar;117(3);368-379.

68. Willenbrock K, Brauninger A, Hansmann ML. Frequent occurrence of B-cell lymphomas in angioimmunoblastic T-cell lymphoma and proliferation of EpsteinBarr virus-infected cells in early cases. Br J Haematol 2007 Sep;138(6);733-739.

69. Patsouris E, Noel H, Lennert K. Angioimmunoblastic lymphadenopathy--type of T-cell lymphoma with a high content of epithelioid cells. Histopathology and comparison with lymphoepithelioid cell lymphoma. Am J Surg Pathol 1989 Apr;13(4);262-275.

70. Willenbrock K, Roers A, Seidl C, Wacker HH, Kuppers R, Hansmann ML. Analysis of T-cell subpopulations in T-cell non-Hodgkin's lymphoma of angioimmunoblastic lymphadenopathy with dysproteinemia type by single target gene amplification of T cell receptor- beta gene rearrangements. Am J Pathol 2001 May;158(5);1851-1857.

71. Lee SS, Rudiger T, Odenwald T, Roth S, Starostik P, Muller-Hermelink HK. Angioimmunoblastic T cell lymphoma is derived from mature T-helper cells with varying expression and loss of detectable CD4. Int J Cancer 2003 Jan 1;103(1);12-20. 72. Stacchini A, Demurtas A, Aliberti S et al. The usefulness of flow cytometric CD10 detection in the differential diagnosis of peripheral T-cell lymphomas. Am J Clin Pathol 2007 Nov;128(5);854-864.

73. Karube K, Aoki R, Nomura Y et al. Usefulness of flow cytometry for differential diagnosis of precursor and peripheral T-cell and NK-cell lymphomas: analysis of 490 cases. Pathol Int 2008 Feb;58(2);89-97.

74. Attygalle AD, Chuang SS, Diss TC, Du MQ, Isaacson PG, Dogan A. Distinguishing angioimmunoblastic T-cell lymphoma from peripheral T-cell lymphoma, unspecified, using morphology, immunophenotype and molecular genetics. Histopathology 2007 Mar;50(4);498-508.

75. Vinuesa CG, Tangye SG, Moser B, Mackay CR. Follicular B helper T cells in antibody responses and autoimmunity. Nat Rev Immunol 2005 Nov;5(11);853-865. 
76. Grogg KL, Attygalle AD, Macon WR, Remstein ED, Kurtin PJ, Dogan A. Angioimmunoblastic T-cell lymphoma: a neoplasm of germinal-center T-helper cells? Blood 2005 Aug 15;106(4);1501-1502.

77. Dupuis J, Boye K, Martin N et al. Expression of CXCL13 by neoplastic cells in angioimmunoblastic T-cell lymphoma (AITL): a new diagnostic marker providing evidence that AITL derives from follicular helper T cells. Am J Surg Pathol 2006 Apr;30(4);490-494.

78. Dorfman DM, Brown JA, Shahsafaei A, Freeman GJ. Programmed death-1 (PD-1) is a marker of germinal center-associated T cells and angioimmunoblastic Tcell lymphoma. Am J Surg Pathol 2006 Jul;30(7);802-810.

79. Roncador G, Garcia Verdes-Montenegro JF, Tedoldi S et al. Expression of two markers of germinal center T cells (SAP and PD-1) in angioimmunoblastic T-cell lymphoma. Haematologica 2007 Aug;92(8);1059-1066.

80. Krenacs L, Schaerli P, Kis G, Bagdi E. Phenotype of neoplastic cells in angioimmunoblastic T-cell lymphoma is consistent with activated follicular B helper T cells. Blood 2006 Aug 1;108(3);1110-1111.

81. Xerri L, Chetaille B, Seriari N et al. Programmed death 1 is a marker of angioimmunoblastic T-cell lymphoma and B-cell small lymphocytic lymphoma/chronic lymphocytic leukemia. Hum Pathol 2008 Jul;39(7);1050-1058. 82. Yu H, Shahsafaei A, Dorfman DM. Germinal-center T-helper-cell markers PD-1 and CXCL13 are both expressed by neoplastic cells in angioimmunoblastic Tcell lymphoma. Am J Clin Pathol 2009 Jan;131(1);33-41.

83. Marafioti T, Paterson JC, Ballabio E et al. The inducible T-cell co-stimulator molecule is expressed on subsets of T cells and is a new marker of lymphomas of $\mathrm{T}$ follicular helper cell-derivation. Haematologica Mar;95(3);432-439.

84. Ree HJ, Kadin ME, Kikuchi M, Ko YH, Suzumiya J, Go JH. Bcl-6 expression in reactive follicular hyperplasia, follicular lymphoma, and angioimmunoblastic Tcell lymphoma with hyperplastic germinal centers: heterogeneity of intrafollicular Tcells and their altered distribution in the pathogenesis of angioimmunoblastic T-cell lymphoma. Hum Pathol 1999;30(4);403-411.

85. Yuan CM, Vergilio JA, Zhao XF, Smith TK, Harris NL, Bagg A. CD10 and BCL6 expression in the diagnosis of angioimmunoblastic T-cell lymphoma: utility of detecting CD10+ T cells by flow cytometry. Hum Pathol 2005 Jul;36(7);784-791. 86. de Leval L, Gisselbrecht C, Gaulard P. Advances in the understanding and management of angioimmunoblastic T-cell lymphoma. Br J Haematol 2010 Mar;148(5);673-689.

87. de Leval L, Bisig B, Thielen C, Boniver J, Gaulard P. Molecular classification of T-cell lymphomas. Critical reviews in oncology/hematology 2009 Feb 23.

88. Dogan A, Attygalle AD, Kyriakou C. Angioimmunoblastic T-cell lymphoma. Br J Haematol 2003 Jun;121(5);681-691.

89. Leich E, Haralambieva E, Zettl A et al. Tissue microarray-based screening for chromosomal breakpoints affecting the T-cell receptor gene loci in mature T-cell lymphomas. J Pathol 2007 Sep;213(1);99-105.

90. Pulford K, Lamant L, Espinos E et al. The emerging normal and diseaserelated roles of anaplastic lymphoma kinase. Cell Mol Life Sci 2004 Dec;61(23);29392953.

91. Amin HM, Lai R. Pathobiology of ALK+ anaplastic large-cell lymphoma. Blood 2007 Oct 1;110(7);2259-2267. 
92. Stein H, Foss HD, Durkop H et al. CD30(+) anaplastic large cell lymphoma: a review of its histopathologic, genetic, and clinical features. Blood 2000 Dec 1;96(12);3681-3695.

93. Bonzheim I, Geissinger E, Roth S et al. Anaplastic large cell lymphomas lack the expression of T-cell receptor molecules or molecules of proximal T-cell receptor signaling. Blood 2004 Nov 15;104(10);3358-3360.

94. Ambrogio C, Martinengo C, Voena C et al. NPM-ALK oncogenic tyrosine kinase controls T-cell identity by transcriptional regulation and epigenetic silencing in lymphoma cells. Cancer Res 2009 Nov 15;69(22);8611-8619.

95. Geissinger E, Sadler P, Roth $\mathrm{S}$ et al. Disturbed expression of the T-cell receptor/CD3 complex and associated signaling molecules in CD30+ T-cell lymphoproliferations. Haematologica 2010 May 29.

96. Chiarle R, Voena C, Ambrogio C, Piva R, Inghirami G. The anaplastic lymphoma kinase in the pathogenesis of cancer. Nat Rev Cancer 2008 Jan;8(1);11-23. 97. Piva R, Agnelli L, Pellegrino E et al. Gene expression profiling uncovers molecular classifiers for the recognition of anaplastic large-cell lymphoma within peripheral T-cell neoplasms. J Clin Oncol 2010 Mar 20;28(9);1583-1590.

98. Piva R, Pellegrino E, Mattioli $\mathrm{M}$ et al. Functional validation of the anaplastic lymphoma kinase signature identifies CEBPB and BCL2A1 as critical target genes. $J$ Clin Invest 2006 Dec;116(12);3171-3182.

99. Lamant L, de Reynies A, Duplantier MM et al. Gene-expression profiling of systemic anaplastic large-cell lymphoma reveals differences based on ALK status and two distinct morphologic ALK+ subtypes. Blood 2007 Mar 1;109(5);2156-2164.

100. Trumper L, Pfreundschuh M, Bonin FV, Daus H. Detection of the $t(2 ; 5)-$ associated NPM/ALK fusion cDNA in peripheral blood cells of healthy individuals. Br J Haematol 1998 Dec;103(4);1138-1144.

101. Maes B, Vanhentenrijk V, Wlodarska I et al. The NPM-ALK and the ATICALK fusion genes can be detected in non-neoplastic cells. Am J Pathol 2001 Jun;158(6);2185-2193.

102. Salaverria I, Bea S, Lopez-Guillermo A et al. Genomic profiling reveals different genetic aberrations in systemic ALK-positive and ALK-negative anaplastic large cell lymphomas. Br J Haematol 2008 Mar;140(5);516-526.

103. Lamant L, Pileri S, Sabattini E, Brugieres L, Jaffe ES, Delsol G. Cutaneous presentation of ALK-positive anaplastic large cell lymphoma following insect bites: evidence for an association in five cases. Haematologica Mar;95(3);449-455.

104. Savage KJ, Harris NL, Vose JM et al. ALK-negative anaplastic large-cell lymphoma (ALCL) is clinically and immunophenotypically different from both ALKpositive ALCL and peripheral T-cell lymphoma, not otherwise specified: report from the International Peripheral T-Cell Lymphoma Project. Blood 2008 Apr 2.

105. Feldman AL, Law ME, Inwards DJ, Dogan A, McClure RF, Macon WR. PAX5-positive T-cell anaplastic large cell lymphomas associated with extra copies of the PAX5 gene locus. Mod Pathol 2010 Apr;23(4);593-602.

106. Roden AC, Macon WR, Keeney GL, Myers JL, Feldman AL, Dogan A. Seroma-associated primary anaplastic large-cell lymphoma adjacent to breast implants: an indolent T-cell lymphoproliferative disorder. Mod Pathol 2008 Apr;21(4);455-463.

107. Li S, Lee AK. Silicone implant and primary breast ALK1-negative anaplastic large cell lymphoma, fact or fiction? International journal of clinical and experimental pathology 2009;3(1);117-127. 
108. van der Veldt AA, Kleijn SA, Nanayakkara PW. Silicone breast implants and anaplastic large T-cell lymphoma. Jama 2009 Mar 25;301(12);1227; author reply 1227.

109. Thompson PA, Lade S, Webster H, Ryan G, Prince HM. Effusion-associated anaplastic large cell lymphoma of the breast: time for it to be defined as a distinct clinico-pathological entity. Haematologica Aug 26.

110. Gisselbrecht C, Gaulard P, Lepage E et al. Prognostic significance of T-cell phenotype in aggressive non-Hodgkin's lymphomas. Groupe d'Etudes des Lymphomes de l'Adulte (GELA). Blood 1998 Jul 1;92(1);76-82.

111. Quintanilla-Martinez L, Fend F, Moguel LR et al. Peripheral T-cell lymphoma with Reed-Sternberg-like cells of B-cell phenotype and genotype associated with Epstein-Barr virus infection. Am J Surg Pathol 1999 Oct;23(10);1233-1240.

112. Dupuis J, Emile JF, Mounier N et al. Prognostic significance of Epstein-Barr virus in nodal peripheral T-cell lymphoma, unspecified: A Groupe d'Etude des Lymphomes de l'Adulte (GELA) study. Blood 2006 Dec 15;108(13);4163-4169.

113. Geissinger E, Odenwald T, Lee SS et al. Nodal peripheral T-cell lymphomas and, in particular, their lymphoepithelioid (Lennert's) variant are often derived from CD8(+) cytotoxic T-cells. Virchows Arch 2004 Oct;445(4);334-343.

114. Patsouris E, Engelhard M, Zwingers T, Lennert K. Lymphoepithelioid cell lymphoma (Lennert's lymphoma): clinical features derived from analysis of 108 cases. Br J Haematol 1993 Jun;84(2);346-348.

115. de Leval L, Savilo E, Longtine J, Ferry JA, Harris NL. Peripheral T-cell lymphoma with follicular involvement and a CD4+/bcl-6+ phenotype. Am J Surg Pathol 2001 Mar;25(3);395-400.

116. Rudiger T, Ichinohasama R, Ott MM et al. Peripheral T-cell lymphoma with distinct perifollicular growth pattern: a distinct subtype of T-cell lymphoma? Am J Surg Pathol 2000 Jan;24(1);117-122.

117. Ikonomou IM, Tierens A, Troen G et al. Peripheral T-cell lymphoma with involvement of the expanded mantle zone. Virchows Arch 2006 Jul;449(1);78-87. 118. Huang Y, Moreau A, Dupuis J et al. Peripheral T-cell lymphomas with a follicular growth pattern are derived from follicular helper T cells (TFH) and may show overlapping features with angioimmunoblastic T-cell lymphomas. Am J Surg Pathol 2009 May;33(5);682-690.

119. Bacon CM, Paterson JC, Liu H et al. Peripheral T-cell lymphoma with a follicular growth pattern: derivation from follicular helper $\mathrm{T}$ cells and relationship to angioimmunoblastic T-cell lymphoma. Br J Haematol 2008 Aug 20.

120. Streubel B, Vinatzer U, Willheim M, Raderer M, Chott A. Novel $\mathrm{t}(5 ; 9)(\mathrm{q} 33 ; \mathrm{q} 22)$ fuses ITK to SYK in unspecified peripheral T-cell lymphoma. Leukemia 2006 Feb;20(2);313-318.

121. Feldman AL, Sun DX, Law ME et al. Overexpression of Syk tyrosine kinase in peripheral T-cell lymphomas. Leukemia 2008 Apr 10.

122. Wilcox RA, Sun DX, Novak A, Dogan A, Ansell SM, Feldman AL. Inhibition of Syk protein tyrosine kinase induces apoptosis and blocks proliferation in T-cell non-Hodgkin's lymphoma cell lines. Leukemia 2010 Jan;24(1);229-232.

123. Rudiger T, Geissinger E, Muller-Hermelink HK. 'Normal counterparts' of nodal peripheral T-cell lymphoma. Hematol Oncol 2006 Dec;24(4);175-180.

124. Went P, Agostinelli C, Gallamini A et al. Marker expression in peripheral Tcell lymphoma: a proposed clinical-pathologic prognostic score. J Clin Oncol 2006 Jun 1;24(16);2472-2479. 
125. de Leval L RD, Thielen C, de Reynies A, Huang YL, Delsol G, Lamant L, Leroy K, Brière J, Molina T, Berger F, Gisselbrecht C, Xerri L, Gaulard P. The Gene Expression Profile of Nodal T-Cell Lymphomas Identifies a Molecular Link between Angioimmunoblastic T-Cell Lymphoma (AITL) and Follicular Helper T Cells (TFH), and between CD30+ Peripheral T-Cell Lymphoma and ALK-Negative Anaplastic Large Cell Lymphoma (ALCL). Blood 2006;108;289.

126. Iqbal J, Weisenburger DD, Greiner TC et al. Molecular signatures to improve diagnosis in peripheral $\mathrm{T}$-cell lymphoma and prognostication in angioimmunoblastic T-cell lymphoma. Blood 2010 Feb 4;115(5);1026-1036.

127. Asano N, Suzuki R, Kagami Y et al. Clinicopathologic and prognostic significance of cytotoxic molecule expression in nodal peripheral T-cell lymphoma, unspecified. Am J Surg Pathol 2005 Oct;29(10);1284-1293.

128. Zettl A, Rudiger T, Konrad MA et al. Genomic profiling of peripheral T-cell lymphoma, unspecified, and anaplastic large T-cell lymphoma delineates novel recurrent chromosomal alterations. Am J Pathol 2004 May;164(5);1837-1848.

129. Thorns C, Bastian B, Pinkel D et al. Chromosomal aberrations in angioimmunoblastic T-cell lymphoma and peripheral T-cell lymphoma unspecified: A matrix-based CGH approach. Genes Chromosomes Cancer 2007 Jan;46(1);37-44. 130. Nelson M, Horsman DE, Weisenburger DD et al. Cytogenetic abnormalities and clinical correlations in peripheral T-cell lymphoma. Br J Haematol 2008 May;141(4);461-469.

131. Piccaluga PP, Agostinelli C, Zinzani PL, Baccarani M, Dalla Favera R, Pileri SA. Expression of platelet-derived growth factor receptor alpha in peripheral T-cell lymphoma not otherwise specified. Lancet Oncol 2005 Jun;6(6);440. 


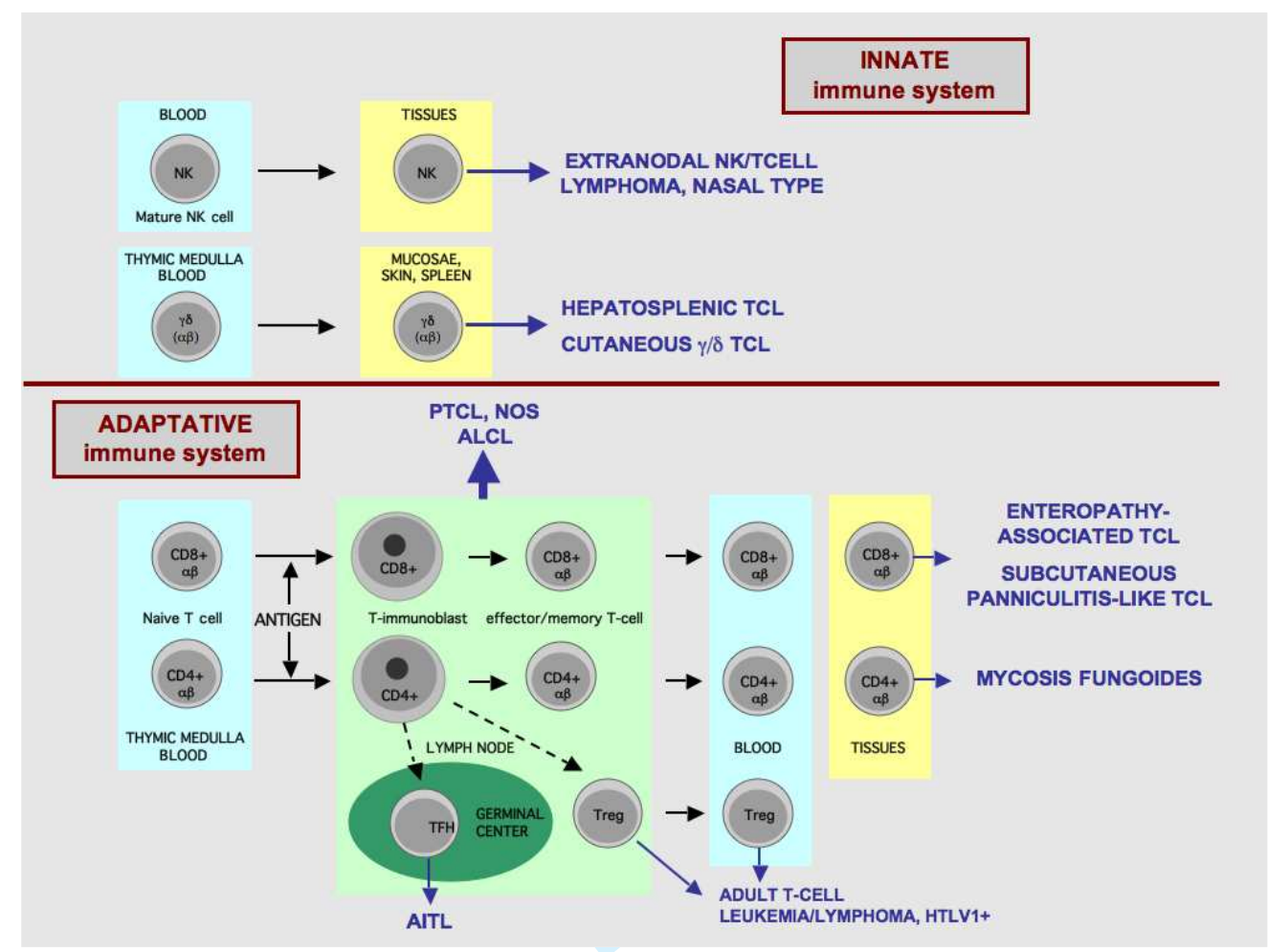



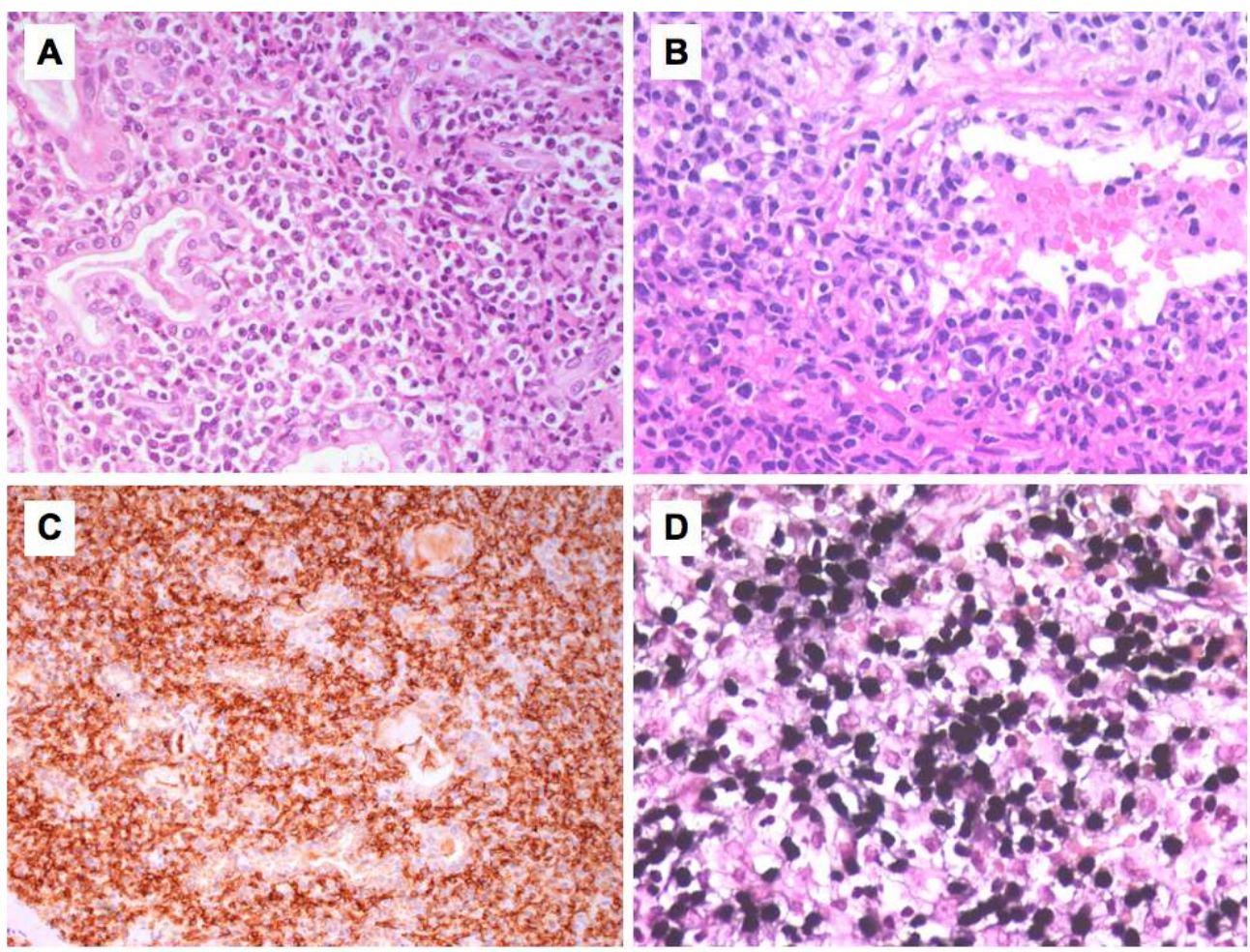


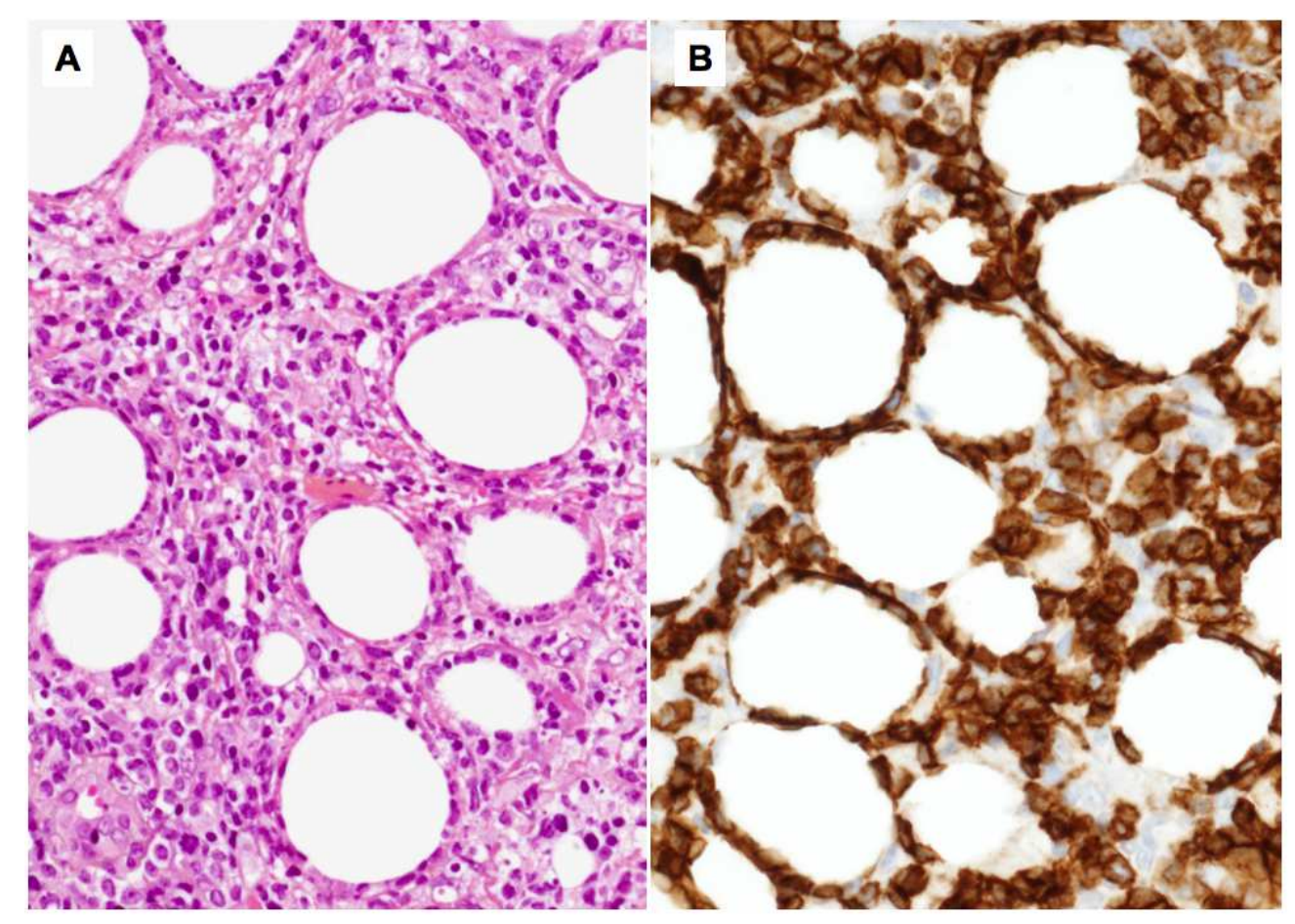




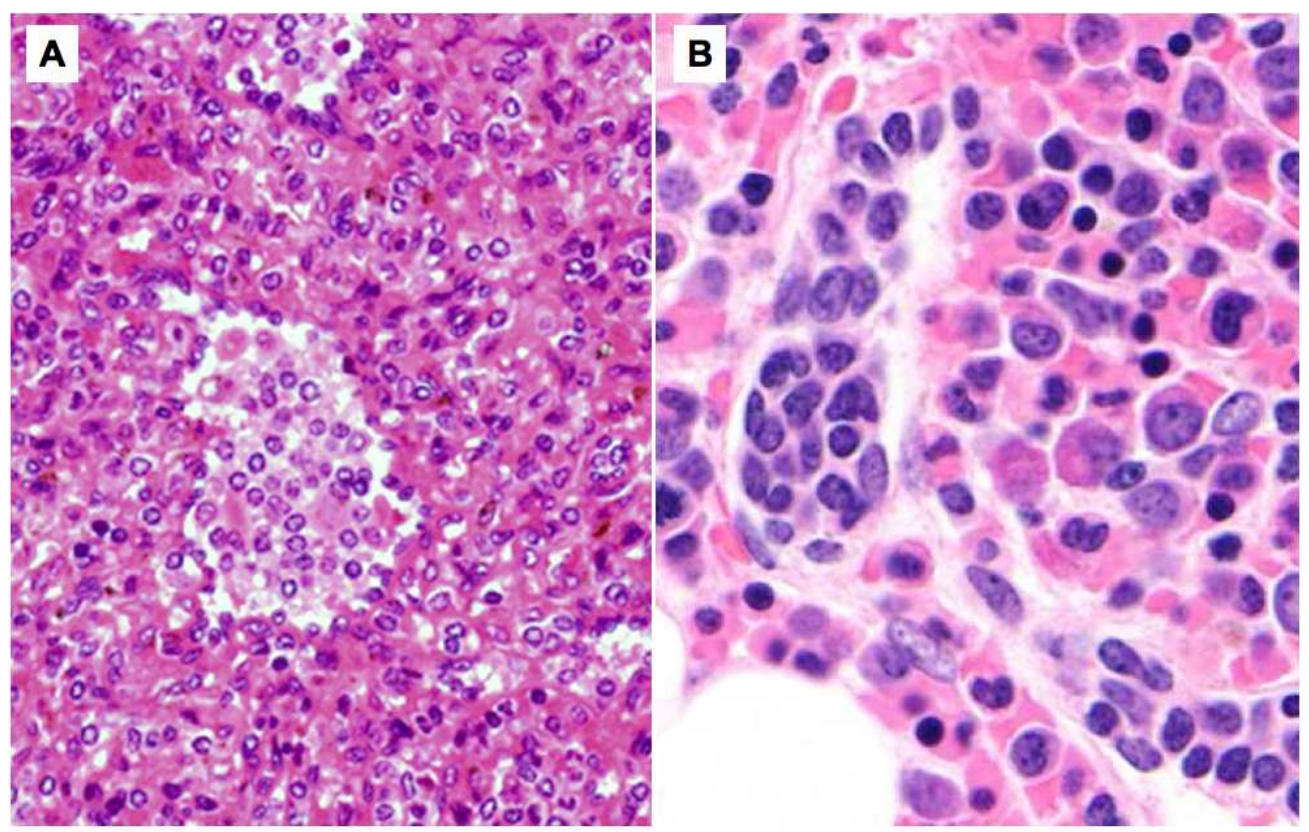



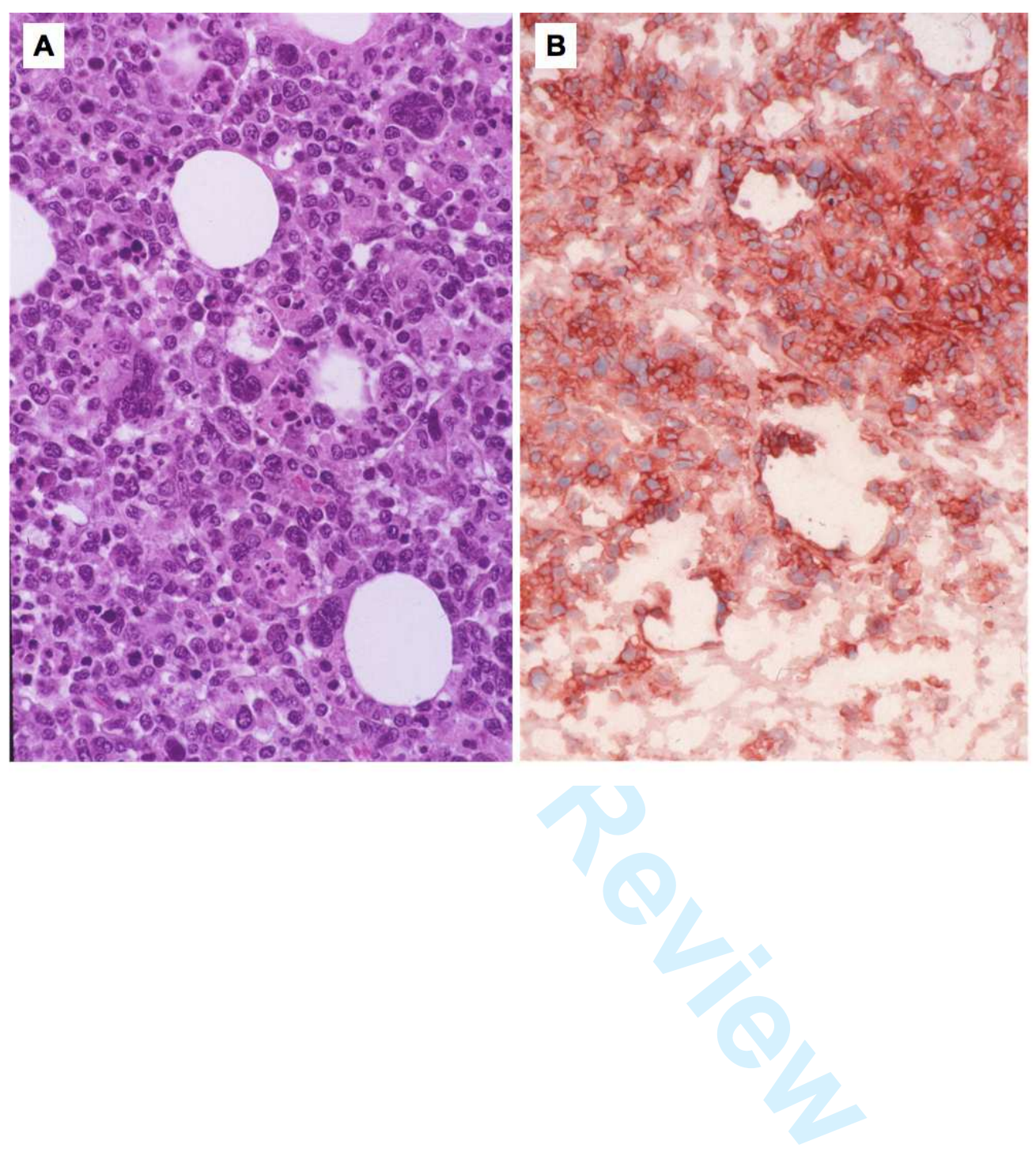


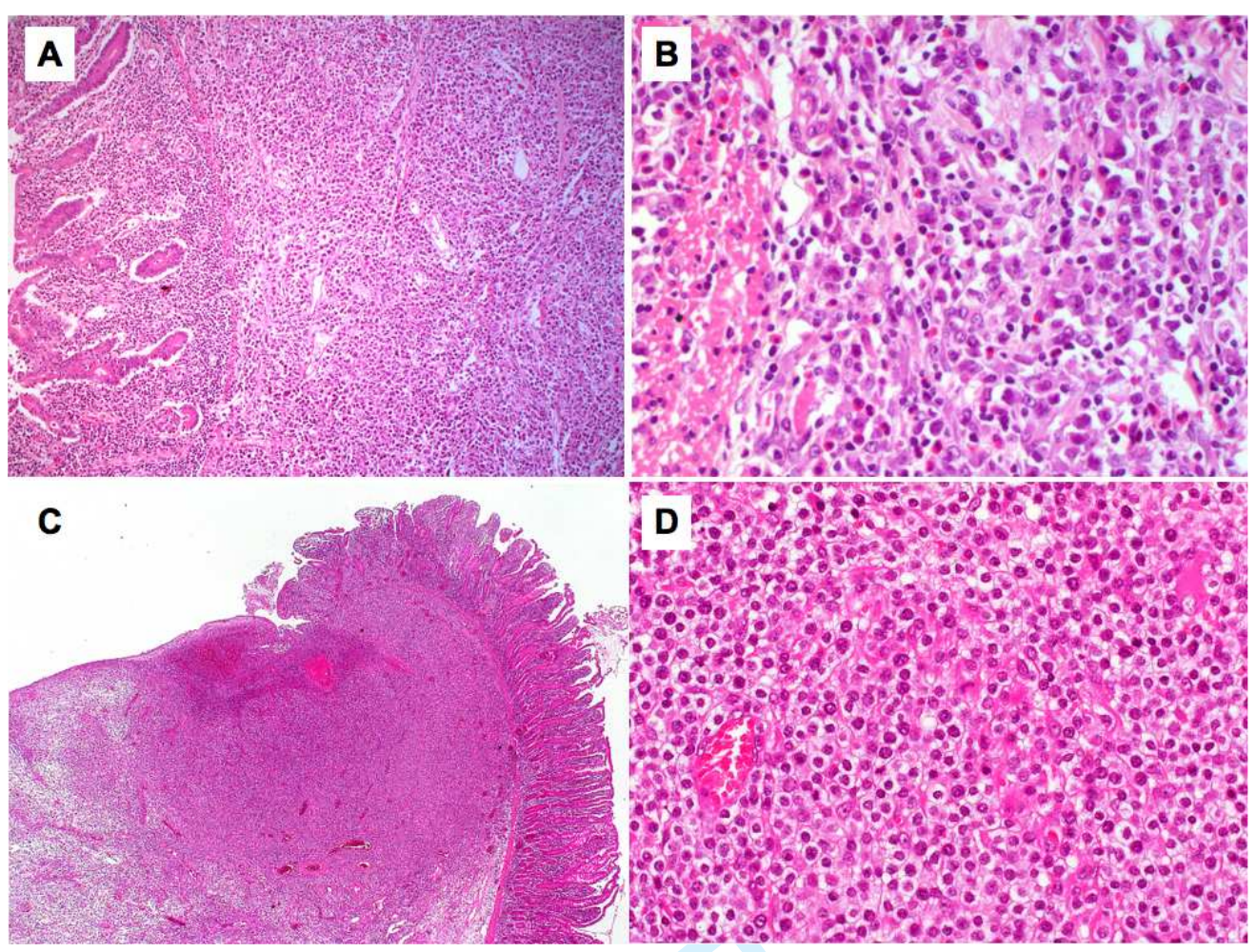



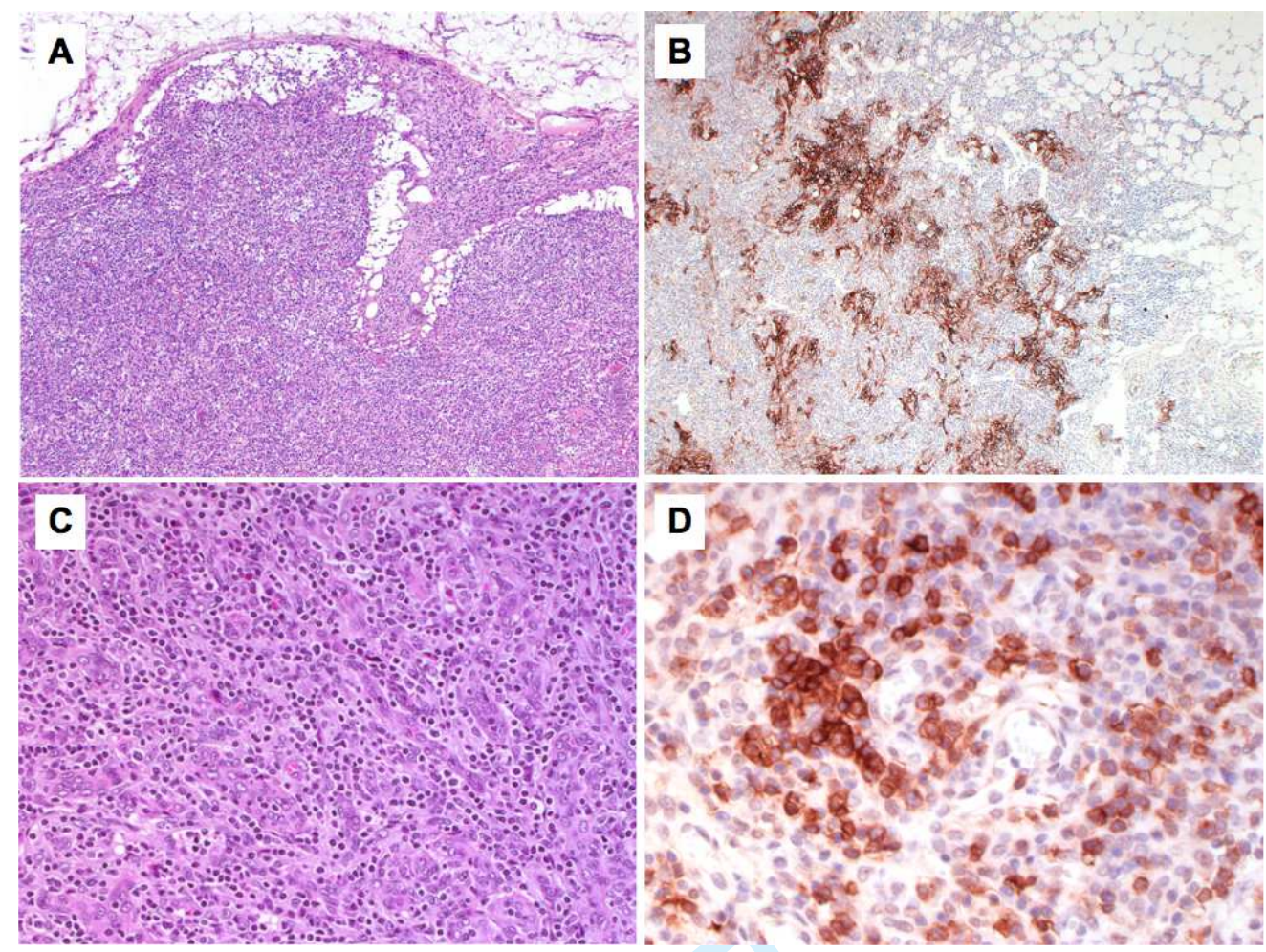


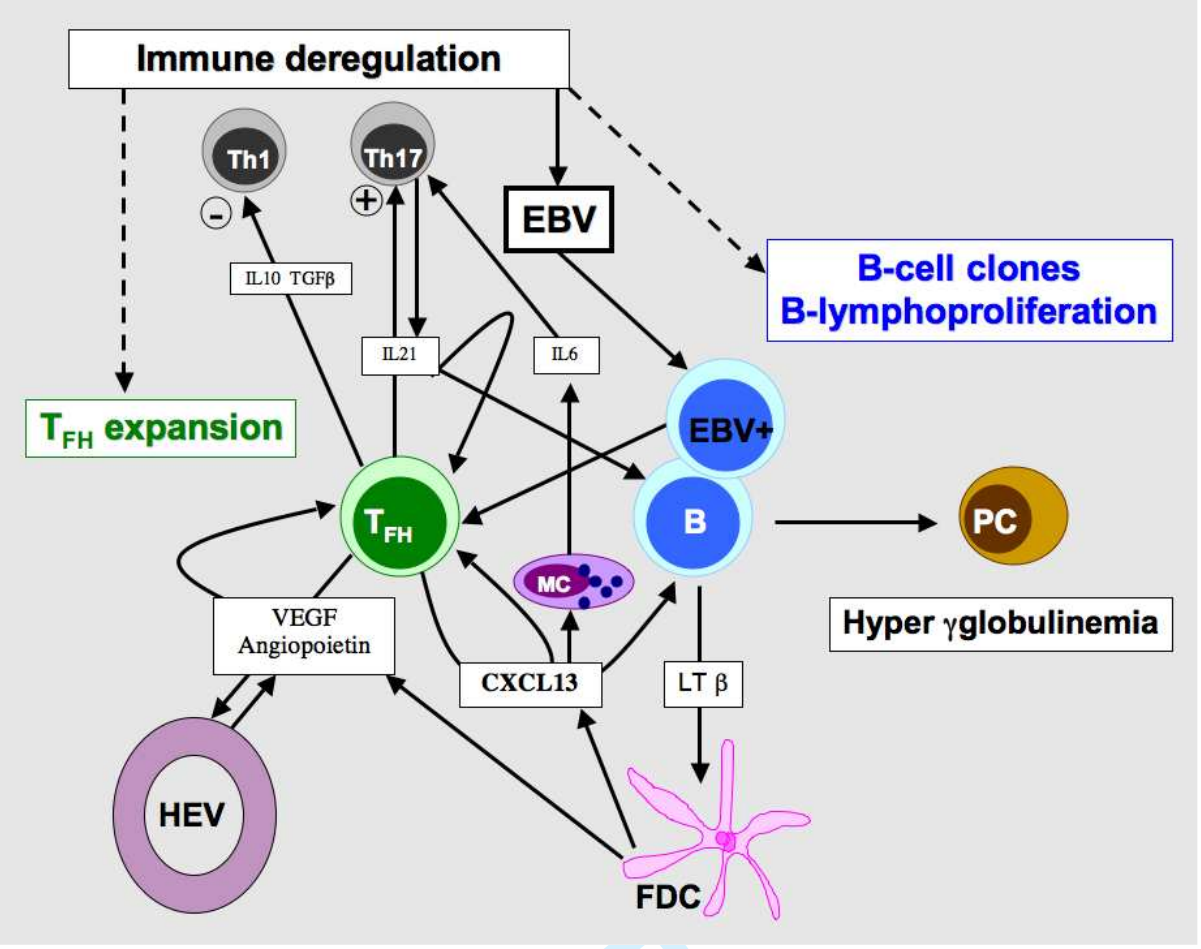








